\title{
Semi-analytical solution for brine leakage through passive abandoned wells taking account of brine density differences
}

\author{
Arnaud Réveillère ${ }^{1}$
}

\section{Abstract}

Both $\mathrm{CO}_{2}$ storage and disposal of waste fluid (e.g., co-produced brine) in deep saline aquifers of sedimentary basins create large scale over-pressurization and tend to displace brine upwards if a vertical connection (e.g., an abandoned well) is present. This raises groundwater pollution issues of brine intrusion into shallower potable water aquifers. When saline brine from the deep aquifer is displaced upwards it lifts and replaces the a priori less saline, less dense water initially filling the connection, resulting in a weight increase that counters leakage. This article presents and explains an innovative semi-analytical solution to this problem of leakage between two aquifers connected by a passive well (represented by a porous column and/or an open wellbore) taking account of the effect of the density difference between lifting and lifted brines during both upward and downward flow. It is based on the linearization of brine density profiles against depth and on two improvements made to the approximate evaluation of convolution products introduced in Nordbotten et al. (2004) for calculation of the pressurization induced by transient flows in open aquifers. The comparison with numerical simulations shows good agreement of results. Since the solution uses time discretization but no spatial grid, computation time is reduced by 3 - 4 orders of magnitude compared to numerical resolution. It does, however, require considering homogeneous aquifers of constant thickness and brine properties.

${ }^{1}$ BRGM. arnaud.reveillere - at - centraliens.net 


\section{Keywords}

Semi-analytical leakage solution, brine density, $\mathrm{CO}_{2}$ geological storage, waste fluid disposal.

\section{Introduction}

Injection into deep saline aquifers is a technique used for disposal of hazardous or non-hazardous liquid waste (Clark et al., 2005, Tsang et al., 2009, Javandel et al., 1988). Fluid disposal into underground formations began in the 1930s, in Texas (USA), when oil producers began injecting co-producedbrine back into the formations. Initially limited to brine disposal, the underground disposal method hasexpanded to hazardous waste since the 1950s. In the 19651980 period, it developed in response to stricter regulations on disposal in surface water bodies (Nordbotten et al., 2004), leading to the construction of more than 130 deep hazardous waste disposal sites. In the 1960s and 1970s, development was accompanied by numerous reports of groundwater contamination relating to abandoned wells (Javandel et al., 1988). Underground disposal of liquid industrial waste, mostly from oil and gas production and from the (petro-)chemical industries, nonetheless continued as a means of isolating injected fluids from the biosphere, under the impetus of stringent surface waste disposal regulations (Clark et al., 2005). In 2000, there were 485 deep injection wells in the US for disposal of industrial liquid waste, with depths of injection zones typically in the 1,500 to 2,500 $\mathrm{m}$ range (Tsang et al. 2008). Approximately, two-thirds of the sites are used for disposal of non-hazardous fluids and one-third for hazardous fluids as defined by the USEnvironment Protection Agency (Clark et al., 2005). Disposal takes place in depleted reservoirs or deep saline aquifers; the latter are the focus of this article.

In addition to fluid disposal, geological storage of $\mathrm{CO}_{2}$ has attracted increasing interest as a way of reducing human-induced climate change. Depleted oil and gas reservoirs, coal seams and deep saline aquifers are seen as possible storage reservoirs, the latter being recognized as having the largest storage 
potential (IPCC, 2005). $\mathrm{CO}_{2}$ storage in deep saline aquifers began in 1996 at Sleipner, in Norway. By 2012, three large scale projects were in operation, storing 2.7 million tons of $\mathrm{CO}_{2} \mathrm{a}$ year in deep aquifers, and three other projects, with an additional target storage capacity of 6 million tons a year, were at the "execute stage" (GCSSI, 2012).

High $\mathrm{CO}_{2}$ injection rates create large scale displacement of the resident brine if there is no pressure relief well. Outside of the $\mathrm{CO}_{2}$ plume footprint, the analytical solution proposed by Mathias et al. (2009) (Equation 37) for pressure buildup in open aquifers shows that pressurization is equal to that which would be created by brine injection at the same volumetric flow rate. Induced brine displacement and possible leakage are therefore also equal. The rest of this article does not consider the case of $\mathrm{CO}_{2}$ storage specificallysince,for the processes of interest, it does not differ from the case of brine injection at the same volumetric injection rate. This article is not concerned with the displacement or leakage of $\mathrm{CO}_{2}$.

Whether for liquid waste disposal or $\mathrm{CO}_{2}$ storage, the deep saline aquifers considered are located in sedimentary basins, below the deepest aquifers designated as potential sources of potable water. Many of these sedimentary basins have been subject to oil and gas exploration and/or production and this has left a large number of wells that penetrate initially competentcaprock formations. Two of the world's most mature oil and gas regions, Texas (USA) and Alberta (Canada), have notably been the subject of review and statistical treatment in order to quantify the spatial distribution of such wells. In the Viking aquifer, in Alberta, representing about one-third of the province's surface area, Gasda et al. (2004) determined that $0.1 \%$ of the area (i.e., $470 \mathrm{~km}^{2}$ ) had a mean density of 17.1 wells $/ \mathrm{km}^{2}$. Nicot (2009) found that in the 23 Texan counties of the Gulf Coast, approximately $2.4 \%$ of the area (i.e., $1,500 \mathrm{~km}^{2}$ ) had morethan 24 wells $/ \mathrm{km}^{2}$. Such abandoned wells - where abandonment procedures may be non-existent, not followed or unenforced, or where cement plugs may be degraded (see e.g., Nicot, 2009) - may represent a direct conduit from the deep saline formations in which injection takes place to shallow fresh water aquifers. Pollution of shallow potable water aquifersresulting from leakage of displaced resident brine through these abandoned wells is therefore an important 
environmental concern. Three modeling approaches exist in the literature for assessing the risk of pollution of an overlying potable water aquifer by storage aquifer brine intrusion: (i) a static method, (ii) dynamic numerical models and (iii) dynamic analytical models.

The static method (Nicot et al., 2009, Bandilla et al., 2012) relies, initially, on computing a critical pressure increase threshold, $\Delta P_{\text {crit }}$, corresponding to the minimum pressure increase beneath the leak required to lift the resident brine in the deep reservoir up to the shallower aquifer, replacing the a priori less saline and less dense water initially filling the leak. Nicot et al. (2009) consider two cases: first the "equilibrium case", where the leaking brine immediately establishes equilibrium with its surroundings and its density depends on the local geothermal gradient and, second, a "constant density" case, where temperature and pressure effects balance each other. The latter has been shown to be less accurate in comparison with numerical simulation cases tested by Birkholzer et al. (2011); this can be explained by the high thermal expansion of brine relative to its low compressibility. In parallel to determining this critical pressure $\Delta P_{\text {crit }}$, injection into the storage aquifer is modeled and the region where the injectioninduced overpressure exceeds $\Delta P_{\text {crit }}$ corresponds to the area where the risk of saline brine intrusion exists. It is called the "Area of Review", i.e., the area where potential connections (e.g., abandoned wells) should be reviewed since the overpressure created by injection can lift the resident brine up to a protected aquifer. This corresponds to a concept recently developed in the United States environment protection legislation, as presented in Birkholzer et al. (2011). We note that both Nicot et al. (2009) and Bandilla et al. (2012) use analytical solutions for this second step, and assume homogeneous reservoirs of constant thickness to estimate the injection-induced overpressure. They therefore obtain a circular Area of Review centered on the injection well, whereas results from numerical simulations could result in more complex shapes if the geological features and heterogeneities of the storage formation are included in the model. This static method can therefore be used to determine an Area of Review, but it necessarily assumes the most conservative case where the two aquifers are connected through an open wellbore (the leak encounters no resistance to flow), and it cannot indicate the volume of brine intrusion. 
Dynamic numerical models are the second method for analyzing the risk of pollution due to saline brine intrusion. They provide additional information such as the leakage rate over time and the volume intruding into the shallow aquifer, which can be used to draw conclusions as to the severity of impact. More importantly, numerical models enable modelingof the effects of an element, typically a cement plug, that slows down the leakage and may prevent the leaking brine from reaching the protected aquifer. Furthermore, leakage is self-limited by the leak flow rate which itself creates a pressure increase in the top aquifer and a pressure decrease in the bottom aquifer. These phenomena could not be included in the static model and numerical models have been used by many researchers to estimate leakage rates between two connected aquifers. Most of these models do not consider the effects of differences in salinity and density between the lifting and lifted brines (e.g., Réveillère et al. 2012), but some do: Birkholzer et al. (2011) consider different brine salinities and compare the results with the static approach presented above. Oldenburg and Rinaldi (2011) consider several instances of evolution of salinity against depth profiles and include brine density variation due to thermal transfer, showing that under some conditions this can create an oscillatory flow regime.

Finally, the third category of methods corresponds to the dynamic analytical solutions. The problem of leakage through a connection between two aquifers has been tackled by several researchers, as reviewed in Nordbotten et al. (2004). The authors conclude that, at that time, quantitative analytical leakage solutions were scarce owing to the mathematical complexity of the solution. Complexity arises from the time-varying flow rate of the leakage which introduces a convolution integral into the expression for pressurization of the aquifers. However, they introduced a step function approximation of the leakage profile history that allows evaluation of the convolution and leads to an algebraic expression for the leakage rate. The authors therefore propose solving for leaking flows through multiple layers and multiple leaking wells. The model was then extended to $\mathrm{CO}_{2}$ leakage (Nordbotten et al., 2005, Nordbotten et al., 2009) and implemented as a boundary condition for representing all overlying layers in a detailed numerical model of the bottom storage aquifer (Dobossy et al., 2011). 
Compared to a static approach, the work described here allows inclusion of cement plugs (modeled asporous media) to calculate the leakage flow rate over time and to quantify intrusion. Compared to dynamic numerical models, this model uses few parameters to describe the problem and is much more computationally efficient. It is, however, limited to homogeneous horizontal aquifer models with uniform properties. Compared to the Nordbotten et al. (2004) analytical solution, the model adds the possibility of accounting for the effects on leakage rate of density differences between lifting and lifted brines, to model open wellbores and leakage decrease after injection has ceased.

Sections below, present a definition of the problem (Sec. 2), the leakage model (Sec. 3), its semi-analytical resolution (Sec. 4) and a comparison of results with those obtained by numerical simulations (Sec. 5).

\section{Problem definition}

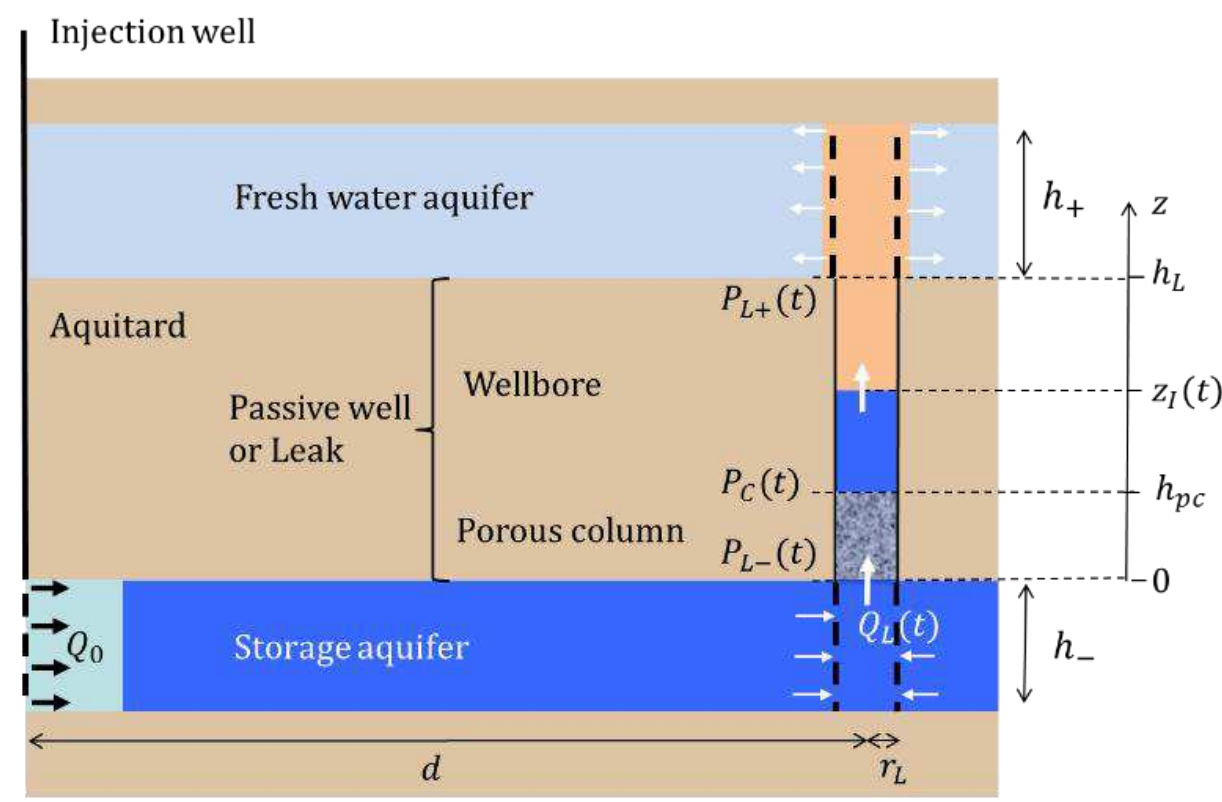

Fresh water; salinity $X_{S+}$

Lifted brine; salinity $X_{S, L 0}$ at the bottom, vertical gradient $\operatorname{grad} X_{S, L}$

Lifting brine; salinity $X_{S-}$

Injected fluid (e.g. brine, $\left.\mathrm{CO}_{2} \ldots\right)$

Figure 1: Schematic diagram of the leakage model. Typically, the lifting brine from the storage aquifer is a dense saline solution; the drinking water aquifer has very low salinity. The lifted brine initially fills the leak (porous column and wellbore). It may have either constant salinity or a vertical salinity gradient. 
We model the subsurface as a stack of alternating permeable layers (aquifers) and impermeable layers (aquitards), which is typical of sedimentary basins. We assume that all aquifers are homogeneous, horizontal and have infinite area and constant thickness. One of the deep saline aquifers is used for geological storage $\left(\mathrm{CO}_{2}\right.$ or liquid waste) with a constant volumetric flow rate $\mathrm{Q}_{0}$ injected from an active injection well at a location $\boldsymbol{x}_{\boldsymbol{I}}$, from time $t_{0}=0$ to $t_{i n j}$. This aquifer is connected to an overlying aquifer via a passive pathway (e.g., abandoned well) of radius $r_{L}$,referred to from now onwards as the leak, at location $\boldsymbol{x}_{\boldsymbol{L}}$. The distance between the injection and the leak is termed $d=\left\|\boldsymbol{x}_{\boldsymbol{I}}-\boldsymbol{x}_{\boldsymbol{L}}\right\|$. The leak is composed of a porous column of length $h_{p c}$, where Darcy's law is applicable (representing, for instance,a degraded cement plug or annular cement), under an open wellbore. Length of both parts can vary, so the leak may represent a pure wellbore (as modeled in the static approaches), a pure porous column (similar to the connection model used in Nordbotten et al., 2004) or a combination of both.

Initially, the system is assumed to be at hydrostatic equilibrium. When injection starts at $t_{0}=0$, the pressure builds up in the storage aquifer. As this occurs, the increase in pressure under the leak $P_{L-}$ drives an upward flow through the leak, the fluid from the storage aquifer lifting and replacing the fluid initially present in the leak (porous column and wellbore). The passive leakage well is therefore acting as a time-varying pumping well with a flow rate into the storage aquifer $Q_{L}\left(Q_{L}>0\right.$ for the upward flow), and time-varying injection into the overlying aquifer at a rate $\frac{\rho_{+}}{\rho_{-}} Q_{L}, \frac{\rho_{+}}{\rho_{-}}$being the ratio of top aquifer density to bottom aquifer density. When injection stops, at $t_{i n j}$, the overpressure in the storage aquifer decreases towards its long term equilibrium value, 0 in the case in point (infinite aquifer). The pressure of the bottom aquifer will therefore not be sufficient to withstand the increased weight of the column of fluid filling the leak (after replacement of the light, lifted brine by the denser lifting brine), and downward flow will start and will continue until return to the initial hydrostatic equilibrium. 
During flow in the leak, the lifted brine (initially filling the leak) is lifted without change in its salinity, and its temperature either equilibrates instantaneously with its surroundings (Thermal equilibrium case), or flows along the leak at its constant initial temperature (Adiabatic flow case).

The model does not include molecular diffusion or convective mixing in the top aquifer; the brine pushed out from the leak during upward leakage therefore accumulates in the top aquifer in a cylindrical shaped plume centered on the top of the leak, the cylinder spreading out from its center during leakage. During the downward flow, the cylinder retracts from its centeruntil it disappears. This determines the salinity of the brine entering the leak from the top.

\section{Leakage model}

\subsection{Pressure equations for the aquifer}

We consider a homogeneous aquifer of constant thickness and infinite extent, with injection at a constant volumetric flow rate $Q\left[\mathrm{~L}^{3} \mathrm{~T}^{-1}\right]$ starting at time $t=0$ at location $\boldsymbol{x}_{\boldsymbol{I}}$. The governing equation of the pressure $\mathrm{P}\left[\mathrm{M} \mathrm{L}^{-1} \mathrm{~T}^{-2}\right]$ in the aquifer is (see e.g., De Marsily 1986):

$$
\begin{gathered}
S \frac{\partial P}{\partial t}-T \nabla^{2} P=\rho g Q \delta\left(\boldsymbol{x}-\boldsymbol{x}_{\boldsymbol{I}}\right) \\
P(\boldsymbol{x}, t=0)=P^{0}
\end{gathered}
$$

\section{Equation 1}

Where $\delta$ is the Dirac function, $t[T]$ the time, $x[L]$ the location, $T\left[\mathrm{~L}^{2} \mathrm{~T}^{-1}\right]$ the transmissivity and $S[-]$ the storativity, expressed by:

$$
\begin{aligned}
& T=\frac{k \rho g h}{\mu} \quad \text { Equation } 2 \\
& S=\rho g \omega h\left(C_{p}+C_{b}\right) \text { Equation } 3
\end{aligned}
$$

$\omega[-], k\left[L^{2}\right]$ and $h[L]$ are respectively the aquifer's porosity, permeability and thickness. $\mu\left[\mathrm{ML}^{-1} \mathrm{~T}^{-1}\right]$ is the fluid's dynamic viscosity and $\rho\left[\mathrm{ML}^{-3}\right]$ its density. $g\left[\mathrm{~L} \mathrm{~T}^{-2}\right]$ is the gravity constant and $C_{p}$ and $C_{b}$ are respectively pore and brine compressibility $\left[\mathrm{M}^{-1} \mathrm{LT}^{2}\right]$.

The solution of Equation 1 has been given by Theis (1935): 


$$
P(\boldsymbol{x}, t)=P^{0}+\frac{Q \mu}{4 \pi k h} E_{1}\left(\frac{\left\|x-x_{I}\right\|^{2} S}{4 T t}\right)
$$

\section{Equation 4}

Therefore, Equation 4 expresses the pressure at any point of the aquifer for a constant injection (or pumping) volumetric flow rate. Since Equation 1 is linear, the pressure perturbation created by a time varying flow rate $Q(t)$ starting at $\mathrm{t}=0$ at the location $x_{L}$ can be deduced using the superposition principle, which introduces a convolution:

$$
P(x, t)=P^{0}+\frac{\mu}{4 \pi k h} \int_{0}^{t} \frac{d Q}{d t^{\prime}} E_{1}\left(\frac{\left\|x-x_{L}\right\|^{2} S}{4 T\left(t-t^{\prime}\right)}\right) d t^{\prime}
$$

\section{Equation 5}

These general equations Equation 4 and Equation 5 can be applied to the two connected aquifers system described in Section 2. We use the subscripts,$+ \quad-$ and ${ }_{L}$ respectively to denote a property of the top aquifer, of the bottom aquifer and of the leak.The pressure above the leak $P_{L+}$ is given by:

$$
P_{L+}(t)=P_{L+}^{0}+\frac{\mu_{+}}{4 \pi k_{+} h_{+}} \frac{\rho_{+}}{\rho_{-}} \int_{0}^{t} \frac{d Q_{L}}{d t^{\prime}} E_{1}\left(\frac{r_{L}^{2} S_{+}}{4 T_{+}\left(t-t^{\prime}\right)}\right) d t^{\prime}
$$

\section{Equation 6}

The pressure under the leak $P_{L-}$ is obtained using the superposition principle to consider the effects of the injection flow rate $Q_{0}$ and transient pumping $Q_{L}$ (Equation 5). Before the end of injection at $t_{i n j}$, the pressure at the leak is given by:

$$
P_{L_{-}}(t)=P_{L_{-}}^{0}+\frac{\mu_{-}}{4 \pi k_{-} h_{-}}\left[Q_{0} E_{1}\left(\frac{d^{2} S_{-}}{4 T_{-} t}\right)-\int_{0}^{t} \frac{d Q_{L}}{d t^{\prime}} E_{1}\left(\frac{r_{L}^{2} S_{-}}{4 T_{-}\left(t-t^{\prime}\right)}\right) d t^{\prime}\right]
$$

\section{Equation 7}

After the end of injection, at $t>t_{i n j}$, the pressure field is obtained by considering a production flow rate $Q_{0}$ starting at $t_{i n j}$ at the same location as that where the injection started at $t=0$. The pressure field is the sum of both: 


$$
\begin{aligned}
P_{L-}(t)=P_{L-}^{0} & +\frac{\mu_{-}}{4 \pi k_{-} h_{-}}\left[Q_{0}\left[E_{1}\left(\frac{d^{2} S_{-}}{4 T_{-} t}\right)-E_{1}\left(\frac{d^{2} S_{-}}{4 T_{-}\left(t-t_{i n j}\right)}\right)\right]\right. \\
& \left.-\int_{0}^{t} \frac{d Q_{L}}{d t^{\prime}} E_{1}\left(\frac{r_{L}^{2} S_{-}}{4 T_{-}\left(t-t^{\prime}\right)}\right) d t^{\prime}\right]
\end{aligned}
$$

\section{Equation 8}

We assume that brine viscosity is a property associated with the storage and overlying aquifers (resp. $\mu_{-}$and $\mu_{+}$), and we neglect the rather small effects of warmer or more saline lifting brine that may flow in the top aquifer.

\subsection{Brine properties in the leak}

Salinity, pressure, and temperature all increase with depth in sedimentary basins. With the two other parameters being constant, brine density increases with pressure or salinity increase, and decreases with temperature increase. Due to the low compressibility of water, the effect of temperature dominates that of pressure, and density therefore decreases with depth for a given constant salinity (see Figure 2). This effect is balanced in case of salinity increase with depth, and the density may even increase with depth for high salinity gradients.

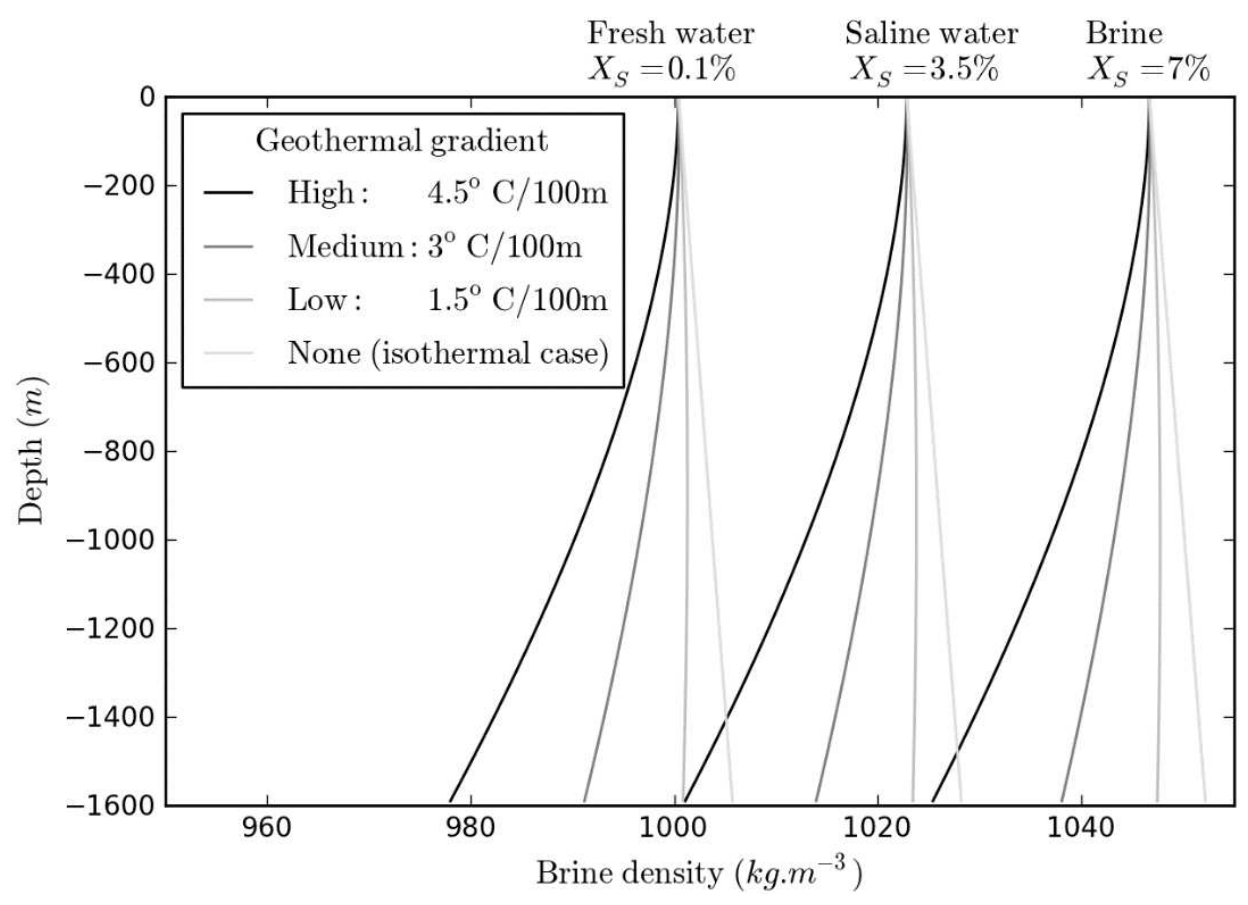

Figure 2: Brine density against depth for several cases of geothermal gradients and salt mass fractions $X_{S}$. A surface temperature of $10^{\circ} \mathrm{C}$, pressure of $10^{5} \mathrm{~Pa}$ and a hydrostatic pressure gradient are assumed. 
Similarly to the static approach taken by Nicot et al. (2009), we use a linear approximation of these brine density profiles $\rho(z)$ for the region of interest, i.e., for a given geothermal gradient and for the appropriate salinity and pressure conditions. We introduce the parameters $\rho_{0, X s}($ density at depth $z=0$ ) and $\xi$ as follows:

$$
\text { Equation 9: } \quad \rho(z)=\rho_{0, X s}+\xi z
$$

In the case of constant salinity $X_{S}$, $\xi$ is written $\xi_{X S}$, and in case of constant temperature and salinity, it is written $\xi_{T, X S}$. We assume that $\xi_{X S}$ and $\xi_{T X S}$ do not depend on the value of the salt mass fraction $X s$.

\subsection{Hydrostatic equations for the leak}

Figure 3 illustrates the initial linearized brine density profile in the leak and its evolution during thermal equilibrium or adiabatic leakage. Since we consider that there is no diffusion and no mass transfer between the inside and outside of the leak, the interface between lifting and lifted brines remains sharp and its position is termed $z_{I}$.

at initial time $t=0$

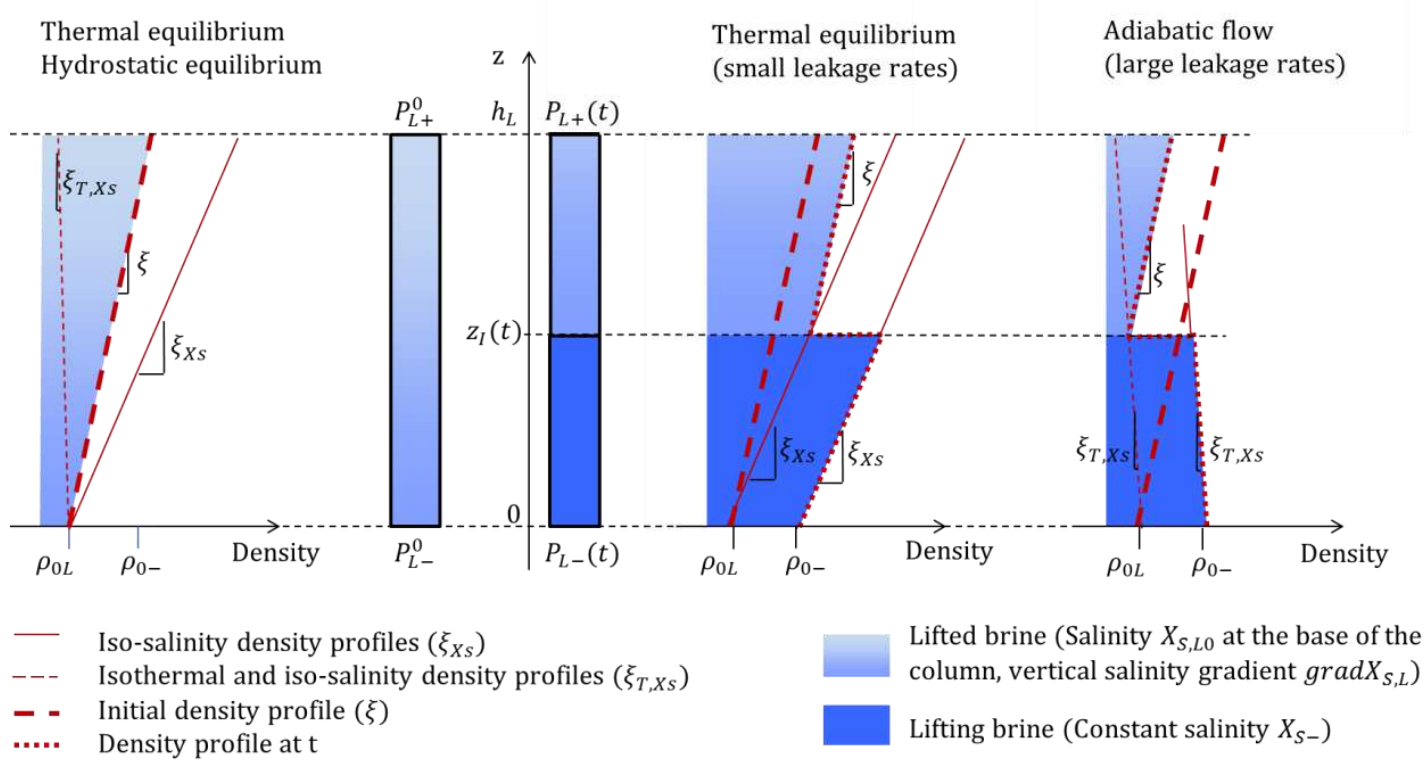

Figure 3: Schematic view of density profile evolution in the leak due to replacement of the lifted brine initially filling the leak by the lifting brine from the bottom aquifer. 
We then express the hydrostatic pressure difference between the bottom and the top of the porous column $\Delta P_{p c}^{\text {static }}$ orof the wellbore $\Delta P_{w b}^{\text {static }}$ in terms of two components: a constant term corresponding to the initial situation (superscript

${ }^{0}$ ) and a first order term based on the density differences between the lifting and lifted brines (superscript ${ }^{1}$ ):

$$
\begin{aligned}
\Delta P_{p c}^{\text {static }}=\Delta P_{p c}^{0}+\Delta P_{p c}^{1}\left(z_{I}\right), & \text { with } \Delta P^{0}{ }_{p c}^{0}=P_{L-}^{0}-P_{C}^{0} \\
\Delta P_{w b}^{\text {static }}=\Delta P_{w b}^{0}+\Delta P_{w b}^{1}\left(z_{I}\right), & \text { with } \Delta P_{w b}^{0}=P_{C}^{0}-P_{L+}^{0}
\end{aligned}
$$

Equation 10 
The first order terms are deduced from the integration of Equation 9:

$$
\Delta P_{p c}^{1}\left(z_{I}\right)=\left\{\begin{array}{cc}
\Delta \rho_{0} g z_{I}+\Delta \xi g z_{I}\left(h_{p c}-\frac{z_{I}}{2}\right) & \text { for } z_{I} \leq h_{p c} \\
\Delta \rho_{0} g h_{p c}+\Delta \xi g \frac{h_{p c}^{2}}{2} & \text { for }_{p c}<z_{I} \leq h_{L}
\end{array}\right.
$$

$$
\begin{aligned}
& \Delta P_{w b}^{1}\left(z_{I}\right) \\
& =\left\{\begin{array}{cc}
0 & \text { for }_{I} \leq h_{p c} \\
\Delta \rho_{0} g\left(z_{I}-h_{p c}\right)+\Delta \xi g\left(z_{I}-h_{p c}\right)\left(h_{L}-\frac{z_{I}-h_{p c}}{2}\right) & \text { for } h_{p c}<z_{I} \leq h_{L}
\end{array}\right. \\
& \text { with } \Delta \rho_{0}=\rho_{0-}-\rho_{0 L} ; \quad \Delta \xi=\left\{\begin{array}{c}
\xi-\xi_{X s} \text { forthermalequilibriumflow } \\
\xi-\xi_{T X S} \text { foradiabaticflow }
\end{array}\right.
\end{aligned}
$$

\section{Equation 11}

Where $\rho_{0-}$ and $\rho_{0 \mathrm{~L}}$ are the densities at $\mathrm{z}=0$ of the lifting and lifted brines respectively. $g\left[L T^{-2}\right]$ is the acceleration due to gravity.

Once the lifting brine has reached the top aquifer, the first order term no longer evolves since the porous column and/or the wellbore are completely filled with the lifting brine from the deep reservoir. The density may still change due to pressure variations in the column, but this brine compressibility effect is negligible compared to its thermal expansion and variation due to salinity.

\subsection{Leakage flow in the porous column}

We apply a macroscopic statement of Darcy's law to the porous column, assuming that the well is vertical and has a constant circular section of radius $r_{\mathrm{L}}$ :

$$
Q_{L}=\pi r_{L}^{2} \frac{k_{p c}}{\mu_{p c}\left(z_{I}\right) h_{p c}}\left(P_{L-}-P_{C}-\Delta P_{p c}^{0}-\Delta P_{p c}^{1}\left(z_{I}\right)\right)
$$

\section{Equation 12}

The gravity terms $\Delta P_{p c}^{0}$ and $\Delta P_{p c}^{1}$ have been presented in the previous section. $\mu_{p c}\left(z_{I}(t)\right)$ is the reference viscosity of the brine at the conditions of temperature, pressure and salinity in the leak at time $t$. 


\subsection{Leakage flow in an open wellbore}

Above the plug, the open wellbore is modeled as the corroded tubing of an abandoned well. The pressure gradient in a flowing well can be represented by a superposition of gravity, frictional, and acceleration gradients.

The gravity term corresponds to the hydrostatic equations in the wellbore (Equation 11). The other two terms are null in absence of flow, and are significant for large leakage rates only. We can therefore assume that the flowing brine is at the temperature of the bottom aquifer (adiabatic leakage case); its density and viscosity are therefore those of the bottom aquifer, respectively $\rho_{-}$and $\mu_{-}$. The pressure loss due to friction forces $\Delta P_{w b}^{\text {fric }}$ is given by the Darcy-Weisbach equation:

$$
\Delta P_{w b}^{\text {fric }}=\frac{\lambda\left(Q_{L}\right) \rho_{0-}}{4} \frac{h_{w b}}{r_{L}}\left(\frac{Q_{L}}{\pi r_{L}^{2}}\right)^{2}
$$

\section{Equation 13}

$\lambda$ is the friction factor and depends on the Reynolds number $R e=\frac{2 Q_{L} \rho_{0-}}{\pi r_{L} \mu_{-}}$, which characterizes the flow regime. It satisfies the following equations:

$$
\begin{gathered}
\lambda=\frac{64}{R e} \text { forRe }<2500 \\
\frac{1}{\sqrt{\lambda}}=-0.87 \log \left(\frac{2.51}{\operatorname{Re} \sqrt{\lambda}}+\frac{0.005}{7.42 r_{L}}\right) \text { for } R e \geq 2500
\end{gathered}
$$

\section{Equation 14}

The equation for turbulent flow $\operatorname{Re}>2500$, known as the "Colebrook equation", is based on experimental data and is given here for very highly corroded tubings (roughness height of $5 \mathrm{~mm}$ ). As it appears in Equation 13, the pressure loss forces are proportional to $Q_{L}^{2}$ and to $r_{L}^{-5}$. They are therefore significant for large leakage rates(i.e., wellbore only, no porous column) and small tubing diameters only.

The acceleration term is negligible. The pressure difference in the wellbore is therefore given by:

$$
P_{C}-P_{L+}=\Delta P_{w b}^{0}+\Delta P_{w b}^{1}\left(z_{I}\right)+\operatorname{sign}\left(Q_{L}\right) \Delta P_{w b}^{\text {fric }}
$$




\section{Equation 15}

\subsection{Conservation of the leaking mass}

We deduce the height of the interface by assuming that the mass of reservoir brine that has leaked is equal to the mass of reservoir brine in the leak, using linear approximation of the density (Equation 9):

$$
\begin{aligned}
& \int_{0}^{t} Q_{L}\left(t^{\prime}\right) d t^{\prime} \\
& =\pi r_{L}^{2} \\
& \cdot\left\{\begin{array}{cl}
\omega_{p c} z_{I}+\frac{\xi_{X S} \omega_{p c} z_{I}^{2}}{2 \rho_{0-}} & \text { for } z_{L-} \leq z_{I} \leq z_{C} \\
\omega_{p c} h_{p c}+\omega_{p c} \frac{\xi_{X s} h_{p c}^{2}}{2 \rho_{0-}}+z_{I}-h_{p c}+\frac{\xi_{X s}}{2 \rho_{0-}}\left(z_{I}-h_{p c}\right)^{2} & \text { for } z_{C}<z_{I} \leq z_{L+}
\end{array}\right.
\end{aligned}
$$

Equation 16

This equation is given for the thermal equilibrium leakage case. For adiabatic flow, $\xi_{\mathrm{Xs}}$ should be replaced by $\xi_{\mathrm{TX}}$.

\section{Leakage solution}

\subsection{Approximation of the convolution product for a} monotonous leakage rate

The convolution products in equations 6 and 7 would normally needto be solved in the Laplace domain, numerically or analytically for simple problems. Alternatively, Nordbotten et al. (2004) propose to approximate the leakage history $Q$ by $\bar{Q}$, a step function changing from 0 to $Q(t)$ at time $[1-\gamma] t$ :

$$
\bar{Q}\left(t^{\prime}\right)=H\left(t^{\prime}-[1-\gamma] t\right) Q(t)
$$

\section{Equation 17}

$H$ is the Heaviside step function. The authors use a constant value $\gamma=0.92$ for a case of brine leakage through a porous column by comparing this approximate solution to a case solved exactly analytically in the Laplace domain. Similarly, Nordbotten et al. (2005) use two constant parameters for successive leakage of brine and $\mathrm{CO}_{2}$. In this study, we propose use of a fluctuating $\gamma(t)$ 
parameter set in order to ensure that the approximate leakage $\bar{Q}$ and the real leakage $Q$ have the same integrals (i.e., the same leakage volume), as presented in Figure 4 . The parameter is therefore set by:

$$
\int_{0}^{t} Q\left(t^{\prime}\right) d t^{\prime}=\gamma(t) t \bar{Q}(t)
$$

Equation 18

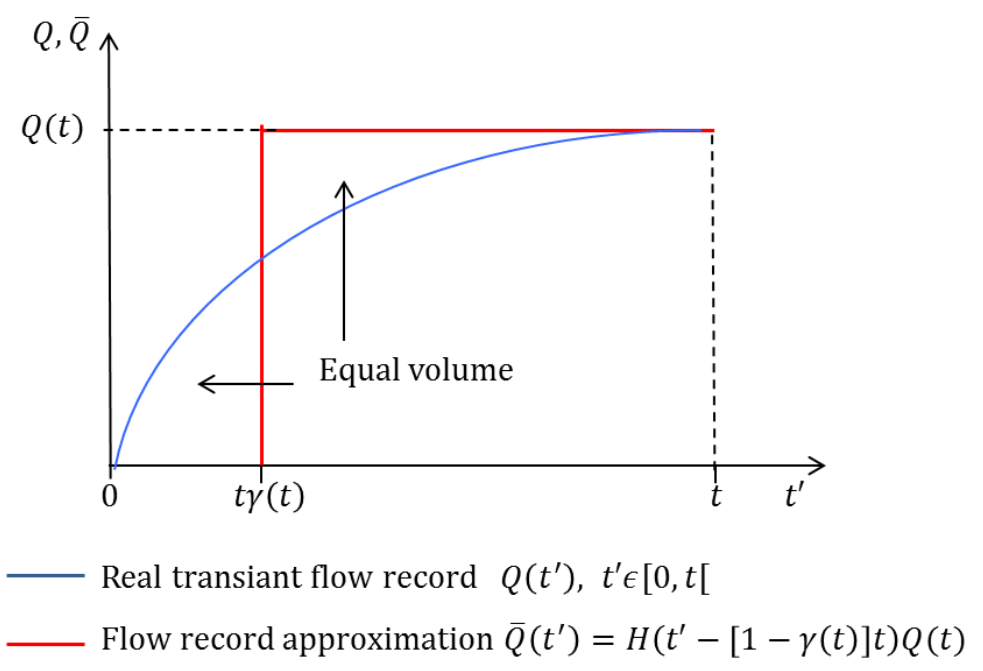

Figure 4: Real leakage record $Q$ and its approximation $\bar{Q}$ introduced in Nordbotten et al., 2004 and modified by using a time-varying $\gamma(t)$ parameter set in order to ensure that both the integrals (i.e., the leakage volume) are equal.

\subsection{Approximation of non-monotonic leakages}

As stated in Nordbotten et al. (2005), this approximation works very well when the leakage has a self-similar form. This not the case for leakage rates when the effects of salinity and density differences between lifted and lifting brines are included. For instance, the numerical simulations by Birkholzer et al. (2011) present results where leakage rates increase, reach a maximum and decrease due to the greater weight of the column of fluid in the leak. The leakage is therefore clearly not self-similar, and the leakage approximation presented in Section 4.1 cannot apply.

We therefore propose to develop non-monotonic leakages into series of monotonic functions, a function being added at every inflexion point. For a piecewise monotonic leakage rate that admits, from time 0 to $\mathrm{t}, \mathrm{m}+2$ local extrema 
at times $\left[\mathrm{t}_{0}=0, \mathrm{t}_{1}, \ldots, \mathrm{t}_{\mathrm{k}}, \ldots, \mathrm{t}_{\mathrm{m}}, \mathrm{t}\right]$, we construct $\mathrm{m}+1$ strictly monotonic functions $Q_{L, k}, k \in[0, m]$, whose sum equals $Q_{L} \cdot Q_{L, k}$ is a continuous function, null from $t_{0}=0$ to $t_{k}$, varying monotonously from $t_{k}$ to $t_{k+1}$, and constant after $t_{k+1}$, as presented in Figure 5. Using this construction, the convolution $\frac{\partial Q_{L}}{\partial t} * W$ can be written:

$$
\int_{0}^{t} \frac{\partial Q_{L}\left(t^{\prime}\right)}{\partial t^{\prime}} W\left(t-t^{\prime}\right) d t^{\prime}=\sum_{k=0}^{m} \int_{0}^{t} \frac{\partial Q_{L, k}\left(t^{\prime}\right)}{\partial t^{\prime}} W\left(t-t^{\prime}\right) d t^{\prime}
$$

\section{Equation 19}

We apply the step function approximation for monotonic functions as described in Section 4.1 to each of these functions $Q_{L, k}$. The convolution $\frac{\partial Q_{L, k}}{\partial t} *$ $W$ can then be approximated by an algebraic expression as follows:

$$
\begin{gathered}
\int_{0}^{t} \frac{\partial \overline{Q_{L, k}}\left(t^{\prime}\right)}{\partial t^{\prime}} W\left(t-t^{\prime}\right) d t^{\prime}=\int_{0}^{t} \frac{\partial H\left(t^{\prime}-\left[1-\gamma_{k}(t)\right] t\right) Q_{L, k}(t)}{\partial t^{\prime}} W\left(t-t^{\prime}\right) d t^{\prime} \\
=Q_{L, k}(t) \int_{0}^{t} \delta\left(\left[1-\gamma_{k}(t)\right] t\right) W\left(t-t^{\prime}\right) d t^{\prime} \\
=Q_{L, k}(t) \cdot W\left(\gamma_{k}(t) \cdot\left[t-t_{k}\right]\right)
\end{gathered}
$$

Equation 20

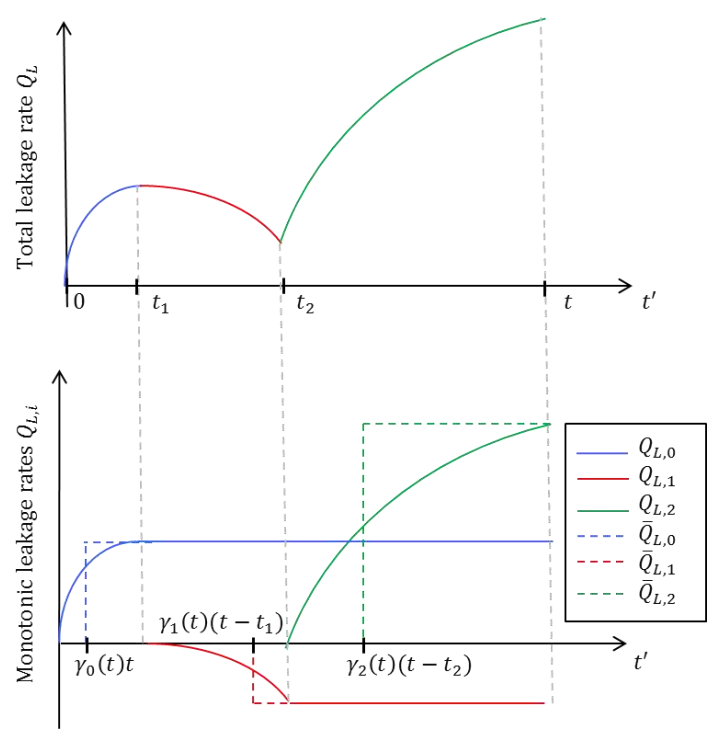

Figure 5: Top panel: schematic representation of a leakage rate function $Q_{L}$ that admits 4 local extrema at times $0, t_{1}, t_{2}$ and $t$. Bottom panel: construction of monotonic functions $Q_{L k}$, whose sum equals $Q_{L}$. Each $Q_{L k}$ record is approximated by a Heaviside step function $\overline{Q_{L, k}}$, as presented in Section 4.1. 
To sum up, the convolution products with time-varying leakage rates $Q_{L}$ are evaluated as follows:

- $\quad Q_{L}$ is broken down into a series of self-similar monotonic functions $Q_{L, k}$

- Every $Q_{L, k}$ function is approximated by a Heaviside step function, which uses a dephasing parameter $\gamma_{k}$. Every $\gamma_{k}$ is time-varying and is evaluated using Equation 18.

Below, we no longer use the notation $\bar{Q}$. We apply this approximation to Equation 6, Equation 7 and Equation 8, which leads respectively to Equation 21, Equation $22\left(\right.$ fort $\left.\leq t_{i n j}\right)$ and Equation 23 fort $>t_{i n j}$.

$$
P_{L+}(t)=P_{L+}^{0}+\frac{\mu_{+}}{4 \pi k_{+} h_{+}} \frac{\rho_{+}}{\rho_{-}} \sum_{k=0}^{m} Q_{L, k}(t) E_{1}\left(\frac{r_{L}^{2} S_{+}}{4 T_{+} \gamma_{k}(t)\left[t-t_{k}\right]}\right)
$$

\section{Equation 21}

$$
P_{L-}(t)=P_{L-}^{0}+\frac{\mu_{-}}{4 \pi k_{-} h_{-}}\left[Q_{0} E_{1}\left(\frac{d^{2} S_{-}}{4 T_{-} t}\right)-\sum_{k=0}^{m} Q_{L, k}(t) E_{1}\left(\frac{r_{L}^{2} S_{-}}{4 T_{-} \gamma_{k}(t)\left[t-t_{k}\right]}\right)\right]
$$

Equation 22

$$
\begin{aligned}
P_{L-}=P_{L-}^{0}+ & \frac{\mu_{-}}{4 \pi k_{-} h_{-}}\left[Q_{0}\left[E_{1}\left(\frac{d^{2} S_{-}}{4 T_{-} t}\right)-E_{1}\left(\frac{d^{2} S_{-}}{4 T_{-}\left(t-t_{\text {inj }}\right)}\right)\right]\right. \\
& \left.-\sum_{k=0}^{m} Q_{L, k} E_{1}\left(\frac{r_{L}^{2} S_{-}}{4 T_{-} \gamma_{k}(t)\left[t-t_{k}\right]}\right)\right]
\end{aligned}
$$

Equation 23 


\subsection{Dimensionless formulation of the problem and solution}

The problem described above can be simplified by considering the dimensionless groupings or functions in Table 2. In the table, the formulations for depthare generic: $\mathrm{z}$ can be replaced by any depth or length, e.g., $\mathrm{z}_{\mathrm{l}}, \mathrm{h}_{\mathrm{pc}}$. The formulation for pressures is also generic, $\mathrm{P}$ can be replaced by $P_{L-}^{0}, P_{L+}^{0}, \Delta P_{c p}^{0}, \Delta P_{w b}^{0}, \Delta P_{c p}^{1}, \Delta P_{w b}^{1}$. Also note that time is not dimensionless since that does not simplify any equation.

$$
\begin{aligned}
& \widetilde{Q_{L}}=\frac{Q_{L}}{Q_{0}} \\
& \tilde{z}=\frac{z}{h_{L}} \\
& \tilde{P}=\frac{4 \pi h_{-} k_{-} P}{Q_{0} \mu_{-}} \\
& \widetilde{\Delta \rho_{0}}=\beta \frac{\Delta \rho_{0}}{\rho_{0-}} \\
& \widetilde{\Delta \xi}=\beta \frac{\Delta \xi h_{L}}{\rho_{0-}} \\
& \beta=\frac{4 \pi h_{-} k g \rho_{0-} h_{L}}{Q_{0} \mu_{-}} \\
& \tau[T]=\frac{\pi r_{L}^{2} h_{L}}{Q_{0}} \\
& \varphi \\
& =\frac{h_{L}}{2 \rho_{0-}} \\
& \cdot\left\{\begin{array}{l}
\xi_{X S} \text { forthermaleq. flow } \\
\xi_{T X_{S}} \text { foradiabaticflow }
\end{array}\right. \\
& \widetilde{\mu_{p c}}=\frac{\mu_{p c}}{\mu_{-}} \\
& \kappa=\frac{\mu_{-} r_{L}^{2} k_{p c}}{4 \mu_{p c} h_{-} k_{-} h_{p c}} \\
& \Lambda \\
& =\operatorname{sign}\left(Q_{L}\right) \lambda \frac{h_{-} k_{-} \rho_{-} h_{L}(1-\delta) Q_{0}}{\pi \mu_{-} r_{L}^{5}} \\
& W_{0}(t)=E_{1}\left(\frac{d^{2} S_{-}}{4 T_{-} t}\right) \\
& \begin{array}{l}
W_{L-}(t) \\
=E_{1}\left(\frac{r^{2} S_{-}}{4 T_{-} t}\right)
\end{array} \\
& W_{L+}(t)=\frac{\mu_{+} \rho_{+} h_{-} k_{-}}{\mu_{-} \rho_{-} h_{+} k_{+}} E_{1}\left(\frac{r^{2} S_{-}}{4 T_{-} t}\right)
\end{aligned}
$$

Table 1: Definition of groupings and functions (dimensionless except time)

The following table presents the dimensionless formulations of the equations describing the problem. 


\begin{tabular}{|c|c|c|}
\hline $\begin{array}{l}\text { Equation } \\
\text { number }\end{array}$ & Dimensionless formulation & $\begin{array}{l}\text { Dimensionless } \\
\text { eq. number }\end{array}$ \\
\hline Equation 10 & $\widetilde{\mathrm{P}_{\mathrm{L}-}^{0}}=\widetilde{\mathrm{P}_{\mathrm{L}+}^{0}}+\widetilde{\Delta \mathrm{P}_{\mathrm{cp}}^{0}}+\widetilde{\Delta \mathrm{P}_{\mathrm{wb}}^{0}}$ & Equation 24 \\
\hline Equation 11 & 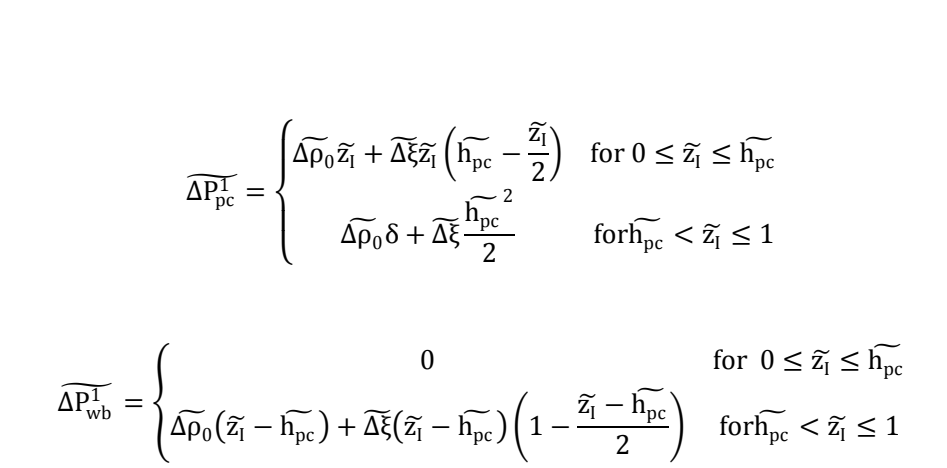 & Equation 25 \\
\hline Equation 12 & $\widetilde{\mathrm{Q}_{\mathrm{L}}}=\frac{\kappa}{\widetilde{\mu_{\mathrm{pc}}}}\left(\widetilde{\mathrm{P}_{\mathrm{L}-}}-\widetilde{\mathrm{P}_{\mathrm{C}}}-\widetilde{\Delta \mathrm{P}_{\mathrm{cp}}^{0}}-\widetilde{\Delta \mathrm{P}_{\mathrm{cp}}^{1}}\right)$ & Equation 26 \\
\hline $\begin{array}{l}\text { Equation } 13 \\
\text { Equation } 15\end{array}$ & $\widetilde{\mathrm{P}_{\mathrm{C}}}=\widetilde{\mathrm{P}_{\mathrm{L}+}}+\widetilde{\Delta \mathrm{P}_{\mathrm{wb}}^{0}}+\widetilde{\Delta \mathrm{P}_{\mathrm{wb}}^{1}}+\Lambda{\widetilde{\mathrm{Q}_{\mathrm{L}}}}^{2}$ & Equation 27 \\
\hline Equation 16 & $\begin{array}{l}\int_{0}^{t} \widetilde{\mathrm{Q}_{\mathrm{L}}}\left(\mathrm{t}^{\prime}\right) \frac{d \mathrm{t}^{\prime}}{\tau} \\
=\left\{\begin{array}{cc}\omega_{\mathrm{C}} \widetilde{\mathrm{z}_{\mathrm{I}}}\left(1+\varphi \widetilde{\mathrm{z}_{\mathrm{I}}}\right) & \text { for } 0 \leq \widetilde{\mathrm{z}_{\mathrm{I}}} \leq \widetilde{\mathrm{h}_{\mathrm{pc}}} \\
\omega_{\mathrm{C}} \widetilde{\mathrm{h}_{\mathrm{pc}}}\left(1+\varphi \widetilde{\mathrm{h}_{\mathrm{pc}}}\right)+\left(1+\varphi\left(\widetilde{\mathrm{z}_{\mathrm{I}}}+\widetilde{\mathrm{h}_{\mathrm{pc}}}\right)\right)\left(\widetilde{\mathrm{z}_{\mathrm{I}}}-\widetilde{\mathrm{h}_{\mathrm{pc}}}\right) & \text { for } \widetilde{\mathrm{h}_{\mathrm{pc}}}<\widetilde{\mathrm{z}_{\mathrm{I}}} \leq 1\end{array}\right.\end{array}$ & Equation 28 \\
\hline Equation 21 & $\widetilde{\mathrm{P}_{+}}(\mathrm{t})=\widetilde{\mathrm{P}_{\mathrm{L}+}^{0}}+\sum_{\mathrm{k}=0}^{\mathrm{m}} \widetilde{\mathrm{Q}_{\mathrm{L}, \mathrm{k}}}(\mathrm{t}) \mathrm{W}_{\mathrm{L}+}\left(\gamma_{\mathrm{k}}(\mathrm{t})\left[\mathrm{t}-\mathrm{t}_{\mathrm{k}}\right]\right)$ & Equation 29 \\
\hline $\begin{array}{l}\text { Equation } 22, \\
\text { Equation } 23\end{array}$ & $\widetilde{\mathrm{P}_{\mathrm{L}}}(\mathrm{t})=\widetilde{\mathrm{P}_{\mathrm{L}-}^{0}}-\sum_{\mathrm{k}=0}^{\mathrm{m}} \widetilde{\mathrm{Q}_{\mathrm{L}, \mathrm{k}}}(\mathrm{t}) \mathrm{W}_{\mathrm{L}-}\left(\gamma_{\mathrm{k}}(\mathrm{t})\left[\mathrm{t}-\mathrm{t}_{\mathrm{k}}\right]\right)+\left\{\begin{array}{c}\mathrm{W}_{0}(\mathrm{t}) \text { fort } \leq \mathrm{t}_{\text {inj }} \\
\mathrm{W}_{0}(\mathrm{t})-\mathrm{W}_{0}\left(\mathrm{t}-\mathrm{t}_{\text {inj }}\right) \text { fort }>\mathrm{t}_{\text {inj }}\end{array}\right.$ & Equation 30 \\
\hline Equation 18 & $\gamma_{k}(t)=\frac{\int_{0}^{t} \widetilde{Q_{L, k}}\left(t^{\prime}\right) d t^{\prime}}{t \widetilde{Q_{L, k}}(t)}$ forkin $[0, m]$ & Equation 31 \\
\hline
\end{tabular}

Table 2: Dimensionless formulation of the problem

The linear system formed by Equation 24, Equation 26, Equation 27, Equation 29 and Equation 30 can be expressed as: 


$$
\mathrm{W}_{0}=\sum_{k=0}^{m} \widetilde{\mathrm{Q}_{\mathrm{L}, \mathrm{k}}}\left[\frac{\tilde{\mu}}{\kappa}+\mathrm{W}_{L-}\left(\gamma_{\mathrm{k}}\left[t-t_{k}\right]\right)+\mathrm{W}_{L+}\left(\gamma_{\mathrm{k}}\left[t-t_{k}\right]\right)\right]+\widetilde{\Delta \mathrm{P}_{\mathrm{wb}}^{1}}+\widetilde{\Delta \mathrm{P}_{\mathrm{cp}}^{1}}+\Lambda\left(\widetilde{\mathrm{Q}_{\mathrm{L}}}\right){\widetilde{\mathrm{Q}_{\mathrm{L}}}}^{2}
$$

\section{Equation 32}

The numerical solution of the problem can then be calculated using an explicit method: the state of the problem at a later time is calculated from the state of the problem at a current time by successively using the followingequations:

- Equation 32, used to calculate the leakage rate $\widetilde{\mathrm{Q}_{\mathrm{L}}}$ at a later time

- Equation 28, used to calculate the lifting-lifted brine interface $\widetilde{\mathrm{z}_{\mathrm{I}}}$ at a later time

- Equation 25, used to calculate pressure changes in the leak at a later time

- Equation 31, used to calculate the $\gamma_{\mathrm{k}}$ parameters at a later time

Solving is straightforward, except for the first step. According to the construction of the leakage rate monotonic components (seeSection 4.2), the only one that is varying at time $t \in\left[t_{i}, t_{i+1}\right], i \leq m$ is $\widetilde{\mathrm{Q}_{\mathrm{L}_{i}}}$. Calculation of the leakage rate $\widetilde{\mathrm{Q}_{\mathrm{L}}}=\sum_{\mathrm{k}=0}^{\mathrm{m}} \widetilde{\mathrm{Q}_{\mathrm{L}, \mathrm{k}}}$ at later time is therefore as follows:

- $\widetilde{\mathrm{Q}_{\mathrm{L}, \mathrm{k}}}$ at later time is equal to $\widetilde{\mathrm{Q}_{\mathrm{L}, \mathrm{k}}}$ at current timefor $k \in[0, m]$ and $k \neq i$.

- $\widetilde{\mathrm{Q}_{\mathrm{L}}, i}$ at later time is calculated using Equation 32 .

The explicit solution is only possible when the tubing pressure loss term $\Lambda\left(\widetilde{\mathrm{Q}_{\mathrm{L}}}\right){\widetilde{\mathrm{Q}_{\mathrm{L}}}}^{2}$ has a secondary influence: its value at current time can be used. If not, animplicit method should be used.

Also note that the number mof local maxima and their times $\left[t_{0}=0, t_{1} \ldots t_{m}\right]$ is not known a priori. A new monotonic leakage component $\widetilde{\mathrm{Q}_{\mathrm{L}, \mathrm{k}}}$ is constructed every time a new local maxima is detected at time $t_{k}$.

\subsection{Leakage driving mechanisms}

Equation 32is detailed below for the case of monotonic leakage (case $t<t_{\text {inj }}$ and $\mathrm{m}=0)$ : 


$$
\begin{aligned}
\underbrace{\mathrm{W}_{0}}_{\begin{array}{c}
\text { Injection } \\
\text { pressurization }
\end{array}}+\underbrace{-\overline{\Delta \mathrm{P}_{\mathrm{wb}}^{1}}-\widetilde{\Delta \mathrm{P}_{\mathrm{c}}^{1}}}_{\begin{array}{c}
\text { Lifting-liftedbrines } \\
\text { densitydifference }
\end{array}}+\underbrace{-\frac{\widetilde{\mathrm{\mu} p c}}{\mathrm{\kappa}} \widetilde{\mathrm{Q}_{\mathrm{L}}}}_{\begin{array}{c}
\text { Porouscolumn } \\
\text { flowresistance }
\end{array}}+\underbrace{-\left[\mathrm{W}_{-}\left(\gamma_{0} \mathrm{t}\right)+\mathrm{W}_{+}\left(\gamma_{0} \mathrm{t}\right)\right] \widetilde{\mathrm{Q}_{\mathrm{L}}}}_{\text {Aquifersflowresistance }} \\
+\underbrace{-\Lambda{\widetilde{\mathrm{Q}_{\mathrm{L}}}}^{2}}_{\begin{array}{c}
\text { tubing } \\
\text { pressureloss }
\end{array}}=0
\end{aligned}
$$

\section{Equation 33}

This equation can be interpreted as a sum of pressure increases or decreases driving the upward flow when positive or the downward flow when negative. The injection pressurization necessarily drives upward flow. Porous column and aquifer flow resistance, as well as tubing pressure loss sign,are opposite to that of $\widetilde{Q_{L}}$, and are null when $\widetilde{Q_{L}}=0$ : these mechanisms counter the flow.

In the thermal equilibrium leakage case, the lifting-lifted brine density difference is also necessarily negative and countering upward flow (the weight of the fluid column increases), whereas in the adiabatic leakage case it can be negative, i.e., the lifting-lifted brine density differences drives the upwards flow along with the injection overpressure. This corresponds to hot lifting brine flowing up without cooling, therefore replacing a colder denser brine and decreasing the weight of the fluid column. Since this term is not necessarily null when $\widetilde{\mathrm{Q}_{\mathrm{L}}}=0$, it can be a driving force by itself.

We also note that the injection pressurization $\mathrm{W}_{0}$ is the only term that does not depend on the leakage rate $\widetilde{\mathrm{Q}_{\mathrm{L}}}$. When developing the exponential integral function $E_{1}$ in series, it shows that $W_{0}(t)$ is a linear function of $\log (t)$. This development is common in hydrogeology, leading to a logarithmic expression of the pressurization (see, e.g., De Marsilly, 1986), and is not detailed in this article. The injection pressurization $\mathrm{W}_{0}$ is therefore unbounded while injection continues, which is typical of flow in an infinite aquifer; a constant pressure boundary condition at some point would bind this continuous pressure increase. The liftinglifted brine density difference is proportional to the sum of $\widetilde{\mathrm{Q}_{\mathrm{L}}}$ over time (i.e., the lifting brine volume in the leak) and constant once all the lifted brine has been pushed out and replaced by the lifting brine; the porous column resistance is proportional to $\widetilde{\mathrm{Q}_{\mathrm{L}}}$ (i.e., Darcy's law), the aquifer's flow resistance is proportional 
to $\widetilde{\mathrm{Q}_{\mathrm{L}}}$ times a logarithmic time dependence, similar to that exposed for the injection term, and finally the tubing pressure losses are proportional to ${\widetilde{\mathrm{Q}_{\mathrm{L}}}}^{2}$. This dependence on time and leakage rate of the different pressure terms of Equation 33 explains the behavior of the leakage over time, which depends, essentially, on which phenomenon predominates.

We may also note that, in the case of equal density for all brines, no open wellbore (and therefore no tubing pressure loss) and supposing a constantdephasing parameter $\gamma$, the model corresponds to Nordbotten et al. (2004) and the leakage rate $\mathrm{Q}_{\mathrm{L}}$ can be obtained by an algebraic expression, time discretization is not needed.

When including the effects of brine density difference, a semi-analytical solution is necessary. Below, the analytical results are obtained using the explicit solution presented in Section 4.3.

\section{Comparison of solutions and results}

\subsection{Numerical model}

In order to compare the semi-analytical model to a numerical one, we consider the case of brine injection in the Dogger aquifer of the Paris basin, which is assumed to be connected to the Albian aquifer, a potable water reserve. Aquifers are modeled using the geometry (seeFigure 6) and parameters (see

Table 3) from Humez et al. (2011).

A three dimensional grid is constructed using local grid refinement techniques (Audigane et al., 2011), as illustrated by Figure 6. The leak uses the vertical symmetry plane and consists of a stack of 820 one-meter high blocks and $21 \times 12.5 \mathrm{~cm}$ horizontal section blocks; this section area is therefore equivalent to that of a circular area of diameter $95 / 8$ inches. The flow is calculated by the TOUGH2 transport code (Pruess et al., 1999). We do not include molecular diffusion or thermal transfer. 


\begin{tabular}{|c|c|c|}
\hline Parameter & $\begin{array}{l}\text { Bottom } \\
\text { aquifer }\end{array}$ & aquifer \\
\hline $\begin{array}{c}\text { Pore } \\
\text { compressibility }\end{array}$ & \multicolumn{2}{|c|}{$4.510^{-10} \mathrm{~Pa}^{-1}$} \\
\hline Porosity & 0.12 & 0.2 \\
\hline Permeability & $10^{-12} m^{2}$ & $6.6710^{-13} \mathrm{~m}^{2}$ \\
\hline
\end{tabular}

Table 3: Aquifer parameters

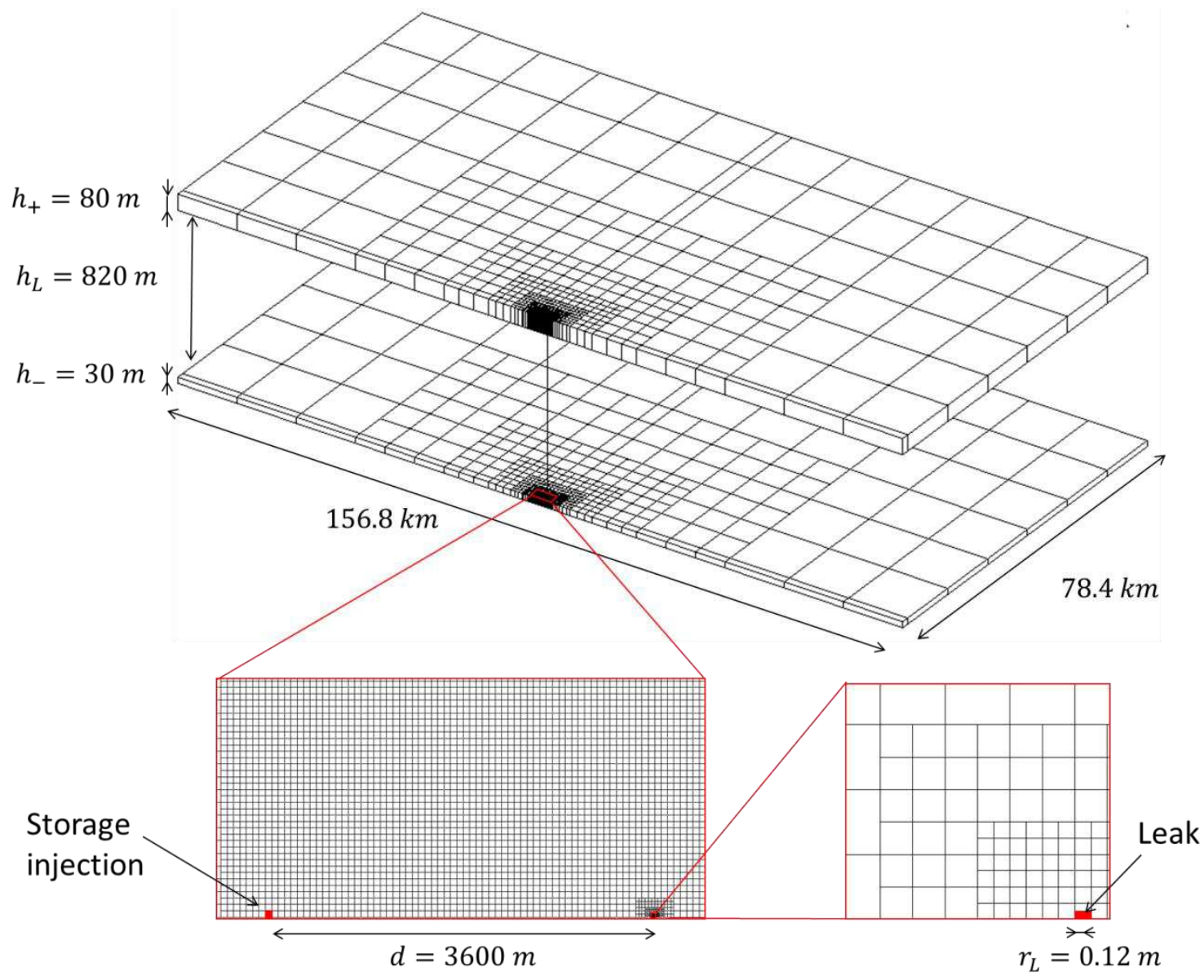

Figure 6: Geometry of test case and spatial grid used in the TOUGH2 numerical simulations.

Initial temperature conditions are $65^{\circ} \mathrm{C}$ at $\mathrm{z}=0$ and with a geothermal gradient of $3^{\circ} \mathrm{C} / 100 \mathrm{~m}$. Initial pressure conditions are $146.10^{5} \mathrm{~Pa}$ at $\mathrm{z}=0$ and hydrostatic equilibrium. A constant volumetric injection flow rate $Q_{0}=$ $200 \mathrm{~m}^{3} \mathrm{~h}^{-1}$ is injected.Fresh water is initially filling the leak and the top aquifer $\left(X_{s+}=X_{s, L 0}=0.1 \% ; \operatorname{grad} X_{s, L}=0\right)$. The salt mass fraction $X_{s-}$ of the lifting 
brine from the bottom aquifer will vary. The duration of injection and of relaxation time modeled after injection ceases, as well as brine salt mass fractions and the leak model vary in the three following examples.

The density and viscosity correlations used in TOUGH2 (Battistelli et al., 1997; Phillips et al., 1981) will also be used in the analytical model, with using the implementation of the CAMELOT code (Bandilla et al., 2012).

\subsection{Example 1: Leak modeled as a porous column}

In a first example, we consider storage injection with during $t_{i n j}=5$ years followed by a 15 year relaxation period. The leak is modeled as a porous column of $15 \%$ porosity and permeability of $10^{-11} \mathrm{~m}^{2}$.

Figure 7 shows the effect of varying the salt mass fractions $X_{S_{-}}$in the bottom aquifer for the semi-analytical solution and the TOUGH2 numerical simulation. It shows very good agreement between numerical and semi-analytical results, except for the decrease in downward flow (see e.g., the $X_{S_{-}}=7 \%$ case at 10 years).This difference is due to the numerical diffusion that occurs with TOUGH2, whereas no diffusion is included in the analytical model. The numerical diffusion mixes the lifting and the lifted brines in the leak (Figure 8) and in the top aquifer (Figure 9), creating a soft decrease in the weight of the column of fluid in the leak during the downward flow, which therefore evolves smoothly in the TOUGH2 results. The analytical model assumes a sharp interface, which creates rapid change in weight of the fluid in the leak once the lifting brine leaves the top aquifer, and a sharper decrease in downward flow. 

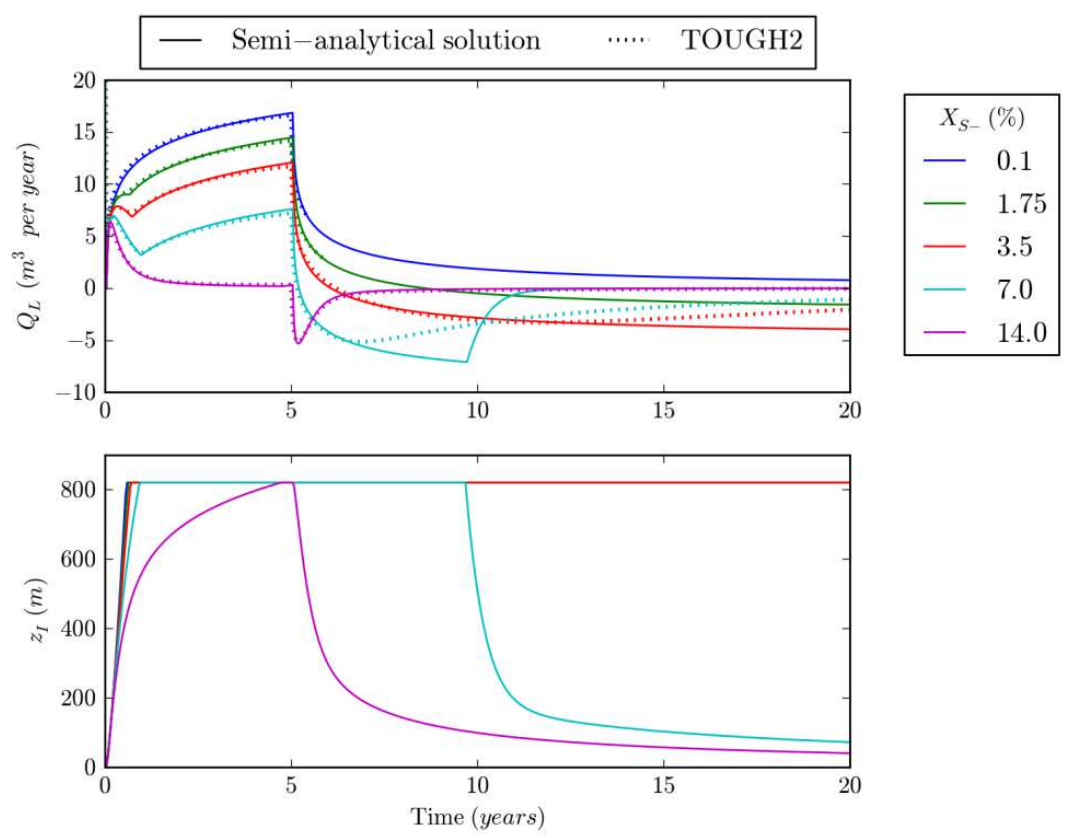

Figure 7: Leakage rate obtained using TOUGH2 or the semi-analytical model (top) and lifting/lifted brines interface position in the leak (bottom) for various cases of lifting brine salt mass fractions $X_{S_{-}}$. The passive well, or leak, is modeled as a porous column (Example 1).
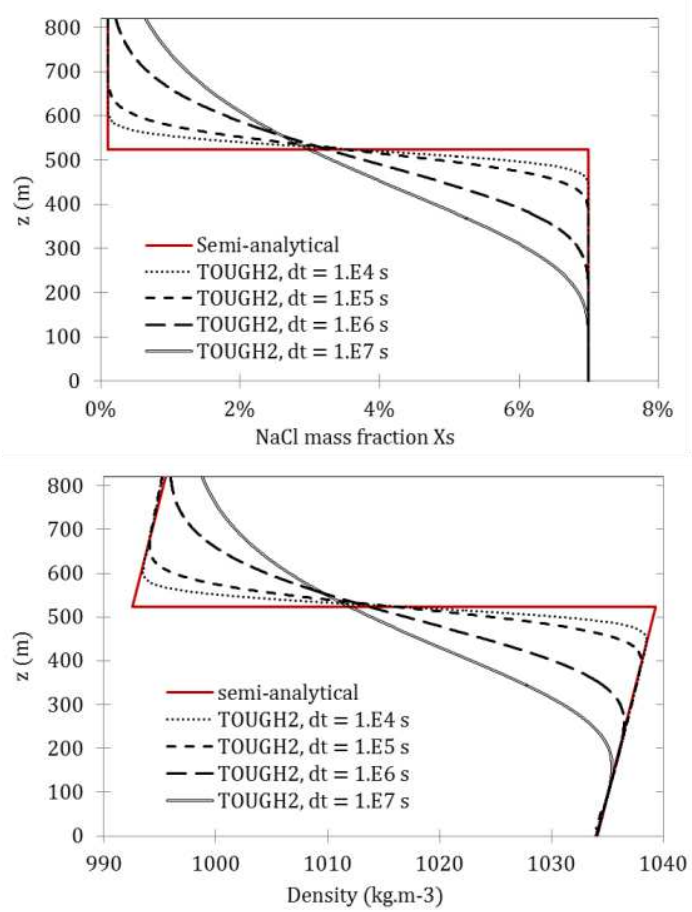

Figure 8: Profile of the salt mass fraction (top) and density (bottom) of brine after 6.45 months of leakage using the semi-analytical model (assumption of a sharp interface) and TOUGH2 numerical simulations for several maximal time steps $d t$ (visible numerical diffusion). Example 1, case $X_{S_{-}}=7 \%$. 


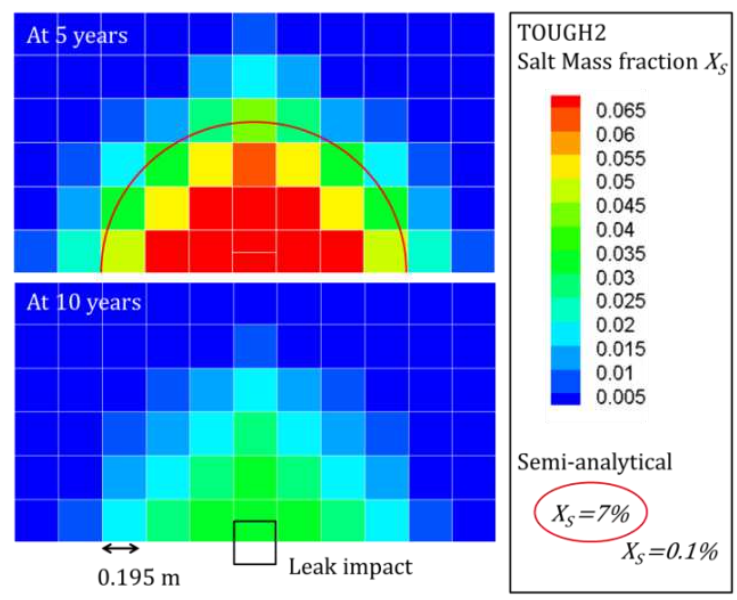

Figure 9: View from the top of the salt mass fraction in the top aquifer obtained using the semi-analytical model (assumption of a sharp interface) and the TOUGH2 with a maximum time step of $10^{5}$ s. Example 1 , case $X_{S_{-}}=7 \%$. Five years corresponds to the end of storage injection. At 10 years, the lifting brine has just left the top aquifer in the semi-analytical solution, whereas saline brine is still present in the numerical results (visible numerical diffusion).

\subsection{Example 2: Leak modeled as both a porous column and an} open wellbore

In this second example we consider the same injection durations as in Example 1 (5 years injection, 15 years relaxation), but the leak is now modeled as a porous column of height $h_{p c}=10$ munder an open wellbore. In the numerical simulation, the open wellbore was modeled using the Equivalent Porous Media (EPM) approach: the flow in the wellbore is modeled as a flow in a porous mediumwith porosity equal to 1 and very high permeability (we chose $10^{-4} \mathrm{~m}^{2}$ ).

The porosity of the porous column is $15 \%$ and its permeability is set to $k_{p c}=1.2210^{-13} \mathrm{~m}^{2}$ in order to obtainequal flow resistance of the porous column in examples 1 and 2 (equal permeability to porous column length ratio). The comparison with TOUGH2 also shows good agreement, except for the decrease in downward flow; this is due to the numerical diffusion issues mentioned above.Minor differences in the upward flow are also observed. Since these differences did not exist when the leak was modeled as a pure porous media, can 
due to the use of a code for transport in porous media for simulating a wellbore flow.
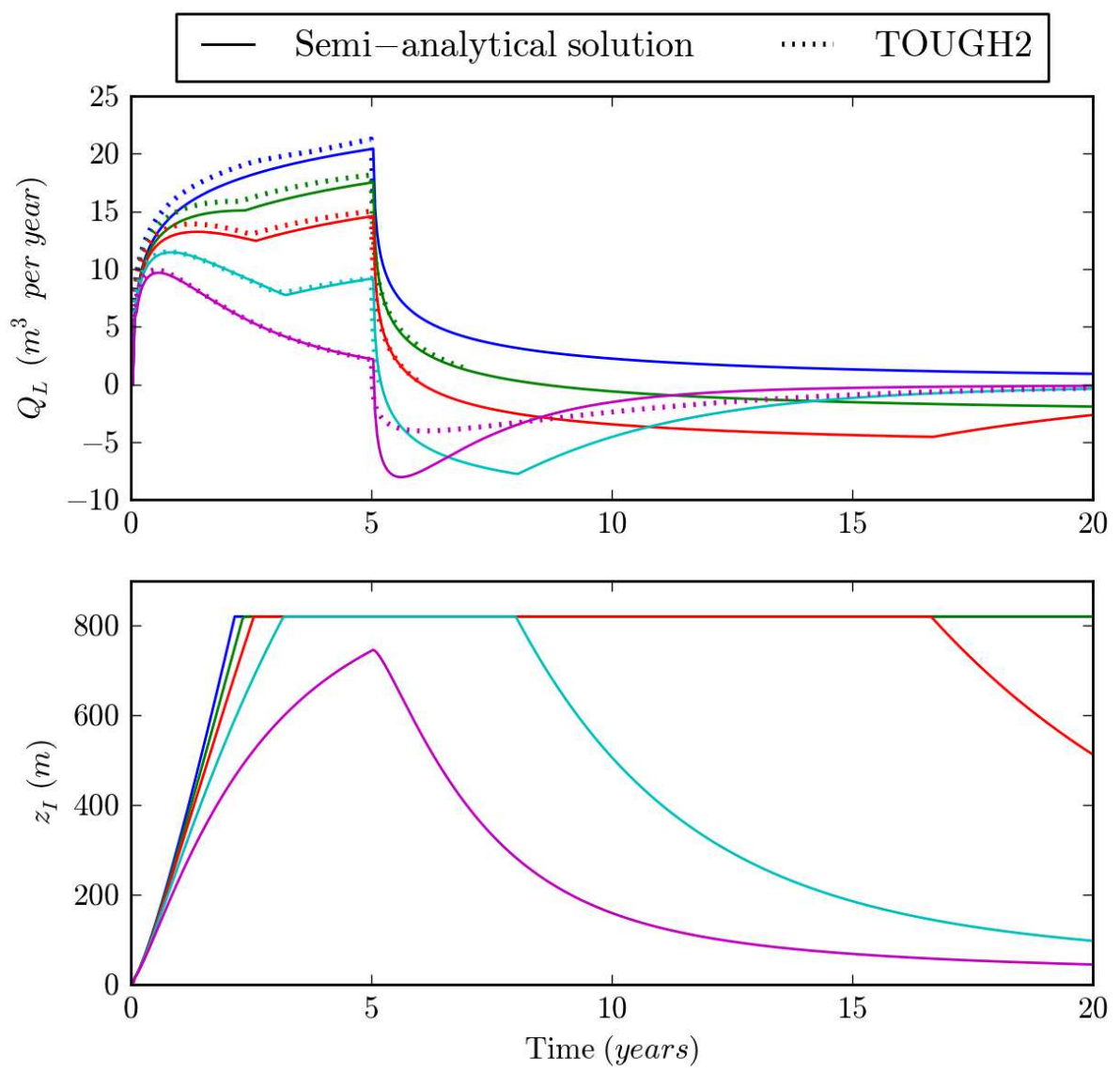

Figure 10: Example 2 of leakage rate over time obtained using TOUGH2 and using the semi-analytical model for various cases of bottom aquifer salt mass fraction $X_{S \text {. }}$ The passive well (or leak) is modeled as a $10 \mathrm{~m}$ high porous column and $810 \mathrm{~m}$ high open wellbore. The lifted brine and top aquifer brine salt mass fractions are $0.1 \%$.

This system evolves in a similar way to Example 1. Since the volume that the lifting brine has to fill before reaching the top of the leak is larger, lifting brine breakthrough into the top aquifer happens later in cases of unequal lifting-lifted salt mass fractions $\left(X_{s_{-}}=1.75 \%\right.$ to $\left.14 \%\right)$.

As shown in Equation 33, different forces are at play for determining the behavior of leakage over time. It can be analyzed as follows for the $X_{S_{-}}=$ 7\%case (Figure 11). During upward flow, the sole driving force is the injection over-pressurization of the bottom aquifer. It is first countered by the leakage 
rateproportional porous column resistance (i.e., Darcy's law), before the liftinglifted brine density difference (proportional to the volume that has leaked) takes over and creates a local minima in the leakage rate at 2.8 years. When injection stops, at 5 years, the storage reservoir over-pressurization $P_{L-}$ quickly decreases until it becomes negative. At that point, the system is not in equilibrium since the reducing over-pressurization cannot withstand the heavier column of lifting fluid. Downward flow therefore begins at 5.1 years, and porous column resistancebegins to counter the downward flow. Once all the lifting brine that had migrated into the top aquifer has flowed down, at 8 years, light water begins filling the leak from the top. The over-weight of the column, i.e., the downward leakage driving force, therefore quickly decreases and leakage flow tends towards zero. The reservoir flow resistance is constantly negligible for such very low flow rates of less than $10 \mathrm{~m}^{3}$ per year.

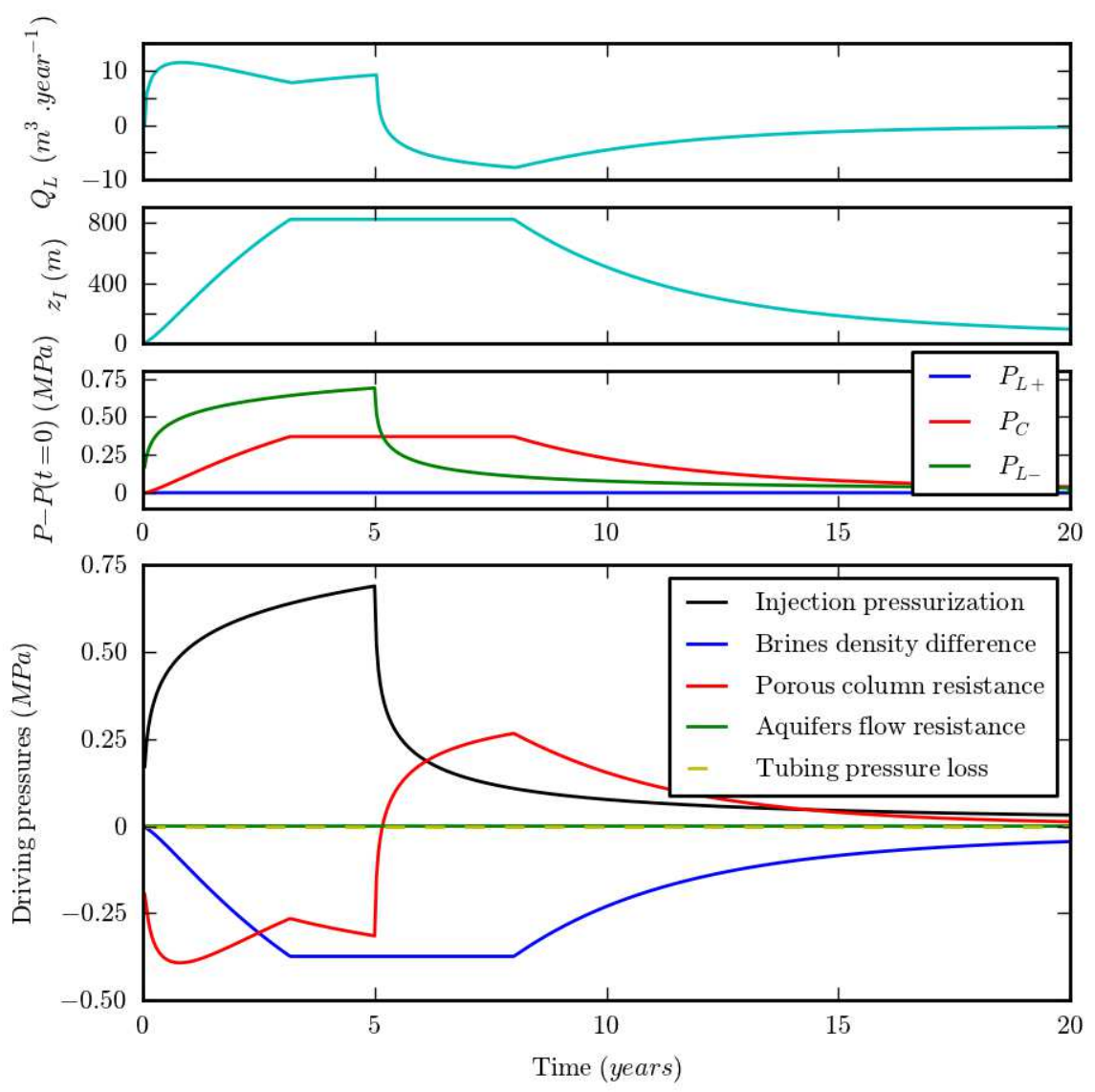

Figure 11: From the highest to lowest panel: leakage rate, lifting-lifted brine interface position, over-pressurization and driving pressures for upward 
(when positive) or downward (when negative) flow over time. Example 2, case $X_{s-}=7 \%$.

Figure 12shows an example of the construction of monotonic leakage functions $Q_{L, k}$, whose sum equals the leakage rate $Q_{L}$, and theirdephasing parameter $\gamma_{k}$, as presented in Section 4. When $\gamma_{k} \rightarrow 1$, the leakage rate $Q_{L, k}$ tends to be a step function and there is no approximation in evaluation of convolution $\frac{\partial Q_{L, k}}{\partial t} * W$ : theTheis (1935) solution expresses the pressurization created by $Q_{L, k}$ in an open aquiferdirectly. The time-fluctuation of $\gamma_{k}$ must therefore be seen as a way of accounting for the pressurization in an open aquifer created by a varying flow rate using a finite sum of step functions, which can easily be dealt with, whereas using an infinite sum leads to a convolution that highly complicates the mathematical resolution.
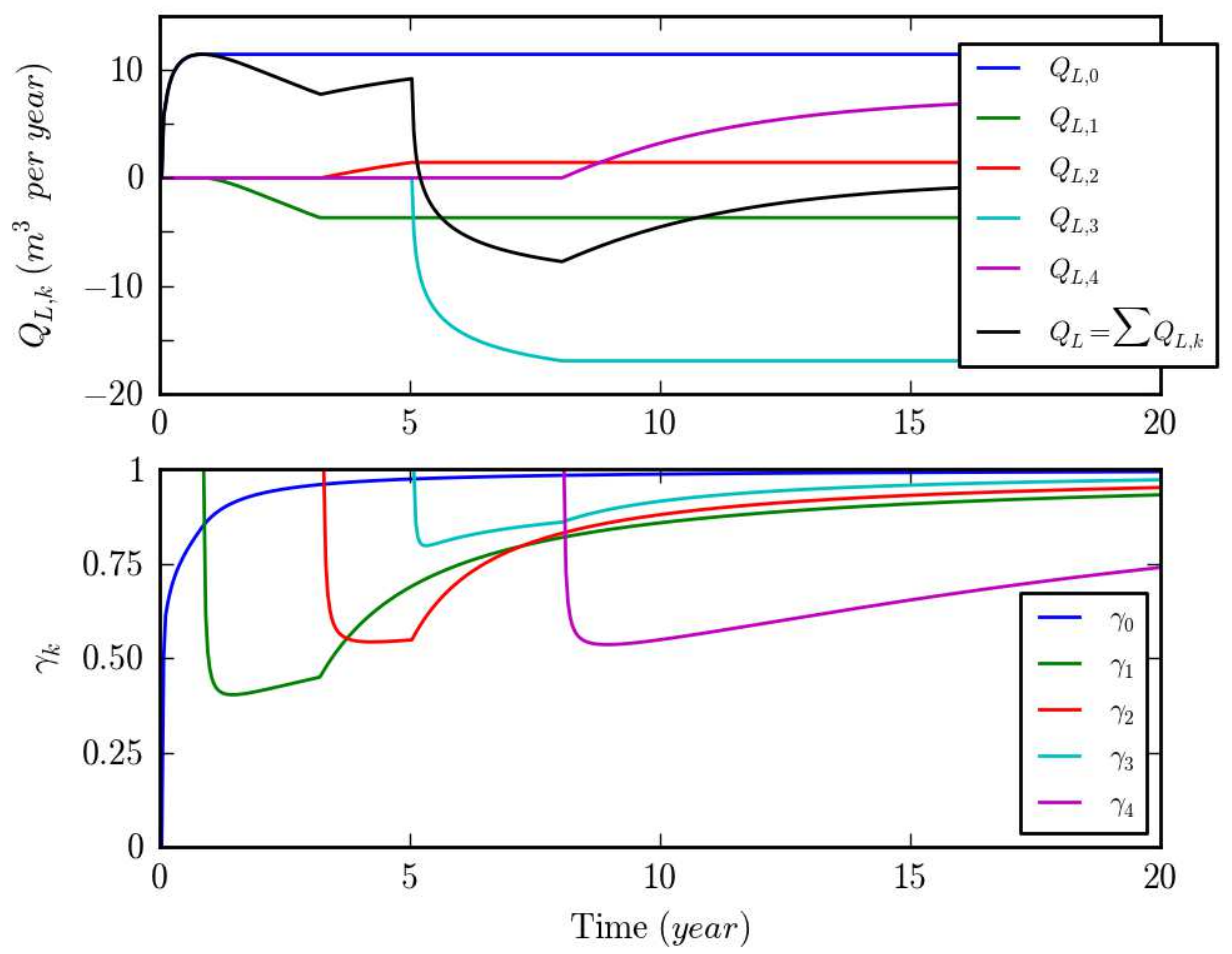

Figure 12: Construction of the leakage rate monotonic components $Q_{L, k}$ (top panel), whose sum equals $Q_{L}$, and the associated $\gamma_{k}$ parameters (bottom panel) that represent the approximation made in the evaluation of the convolution products (there is no approximation when $\gamma_{k}=1$ ). Example 2, case $X_{s-}=7 \%$. 


\subsection{Example 3: Leak modeled as an open wellbore}

In this third example, we consider 35 days of storage injection followed by a 65 day relaxation period, i.e., much shorter periods than in previous examples, since the leakage rates are much higher due to the absence of porous column. Comparison with TOUGH 2 also shows good agreement, as illustrated by Figure 13.The major difference during downward flow for the case $X_{s_{-}}=3.5 \%$ is explained by the numerical diffusion. Minor differences in the upwards flow are observed, which may be due to the Equivalent Porous Media approach for modeling wellbore flow with TOUGH2.
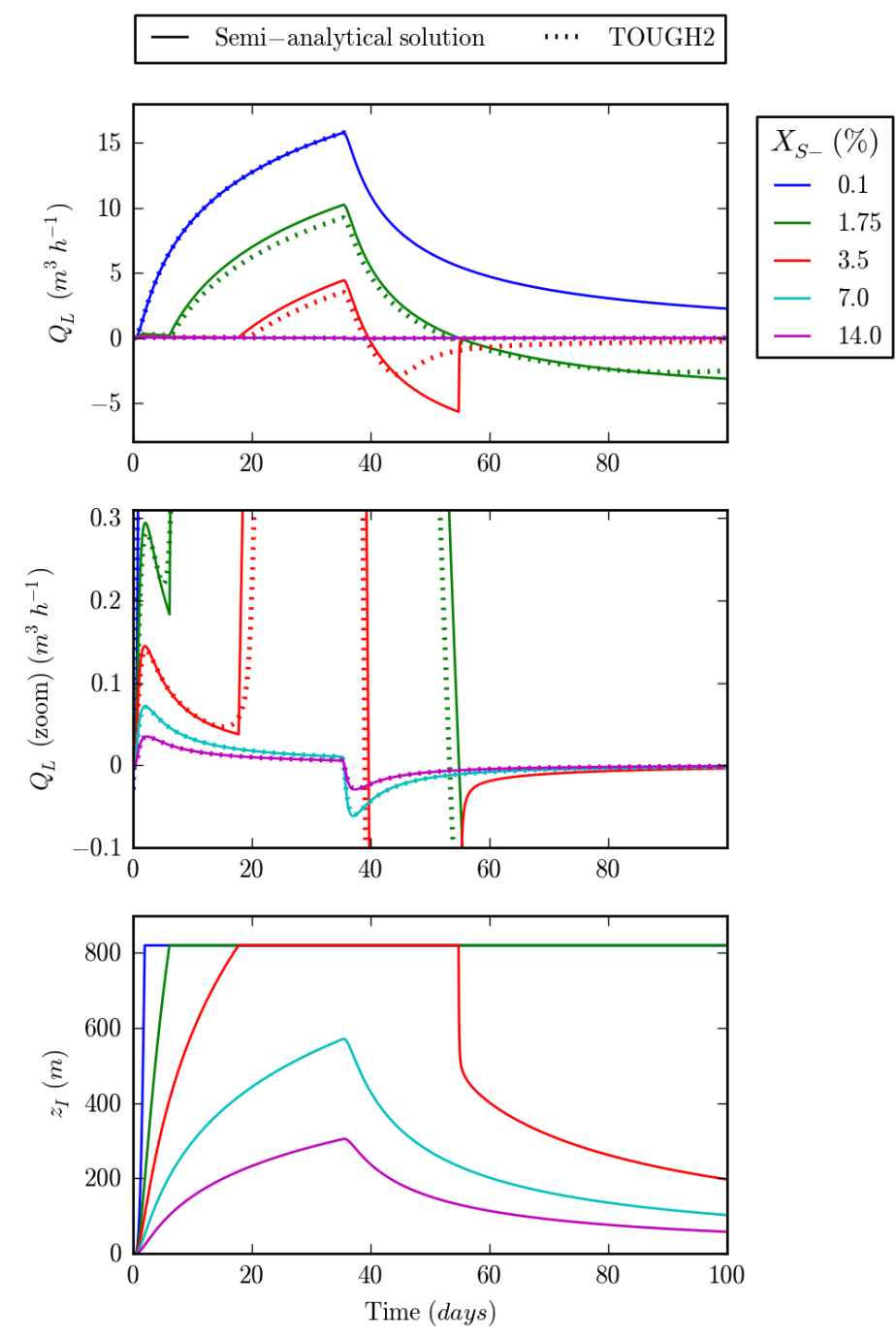

Figure 13: Example 3 of leakage rate over time obtained using TOUGH2 and using the semi-analytical model for various cases of bottom aquifer salt mass fraction $X_{S .}$. The passive well (or leak) is modeled as an empty wellbore. 
As shown in Equation 33, different forces are at play to explain the behavior of the leakage over time. It can be analyzed as follows for the case Xs- = $3.5 \%$ (Figure 14). During upward flow, the sole driving force is the injection overpressurization. It is first countered by the leakage-proportional aquifer flow resistance (i.e., Theis solution), before the lifting-lifted brine density difference (proportional to the volume that has leaked) takes over and creates the first inflexion in the leakage rate, at 2 days. This effect is bounded and becomes constant once the lifting brine has totally replaced the lifted brine, which happens at 18 days, explaining the second inflexion and the sudden increase in the leakage rate. At that point the leakage flow becomes high enough to create a pressure increase in the top aquifer and a visible cusp in pressurization of the bottom aquifer. When injection stops, at 36 days, the reservoir over-pressurization quickly decreases, and so do leakage rate and aquifer flow resistance, which are approximately proportional. When the reducing over-pressurization of the bottom aquifer can no longer withstand the heavier column of lifting fluid, downward flow begins and the aquifer flow resistance increases progressively with the flow. Once all the lifting brine has flowed down, at 58 days, the lifted brine begins to refill the leak from the top. The over-weight of the column, i.e., the downward leakage driving force, reduces rapidly, as do leakage and aquifer flow resistance. The tubing flow resistance remains negligible for this wellbore diameter (equivalent to $95 / 8$ " tubing) and flow rate not exceeding $10 \mathrm{~m}^{3} / \mathrm{h}$. 

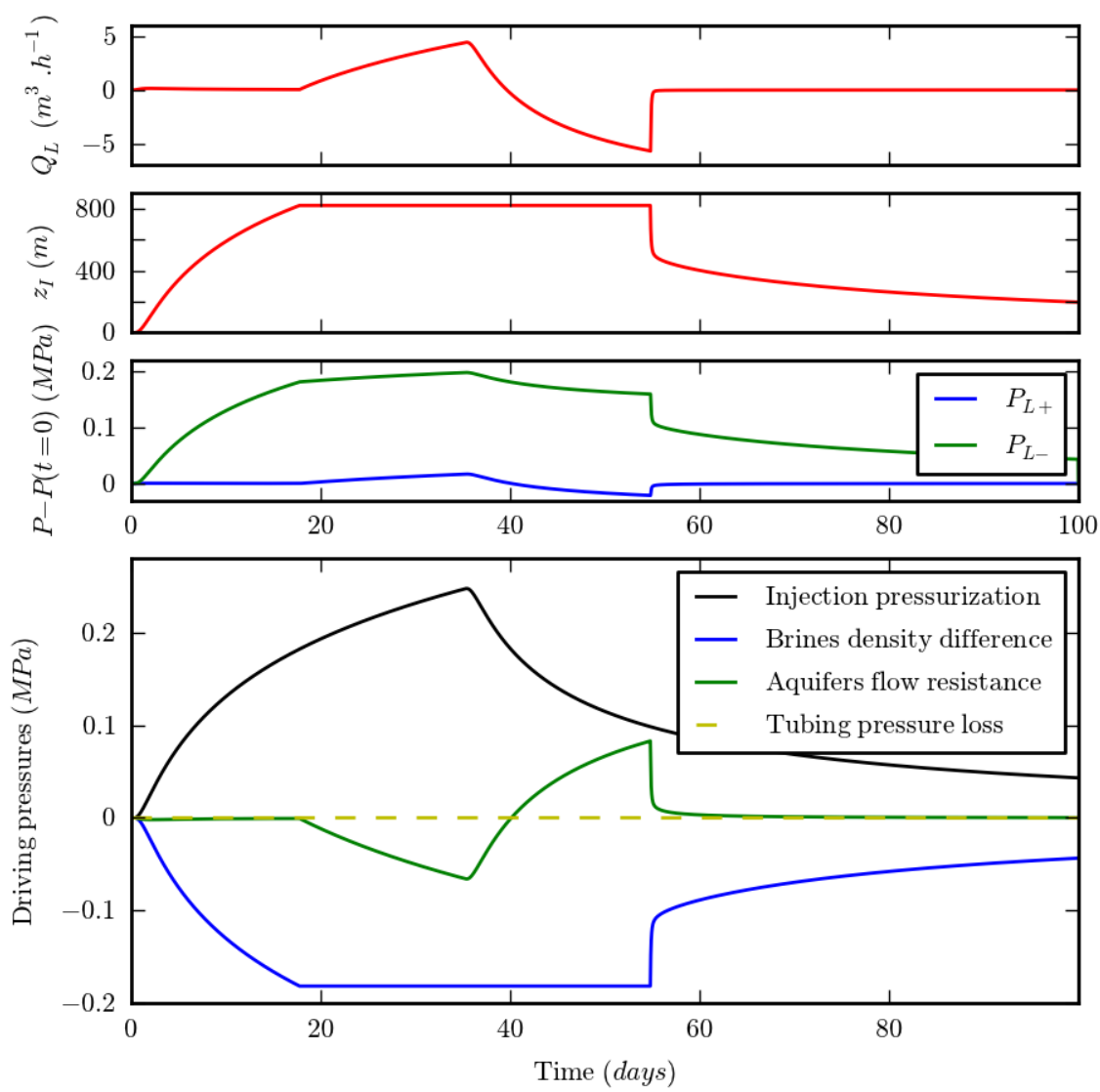

Figure 14:From the highest to lowest panel: Leakage rate, lifting-lifted brines interface position, over-pressurization and driving pressures for upwards (when positive) or downwards (when negative) flow over time. Example 3, case $X_{s-}=3.5 \%$.

Lastly, we can use Example 3 to compare a leakage flow at thermal equilibrium with its surroundings to adiabatic leakage (Figure 15). In the adiabatic leakage situation, the column becomes lighter as lifting fluid fills the leak, thereby encouraging leakage. This results in very rapid leakage at the start, mostly driven by the lighter column of fluid effect. This effect is bounded and becomes constant when the leak is totally filled by hot, light water; it then loses its influence progressively. 

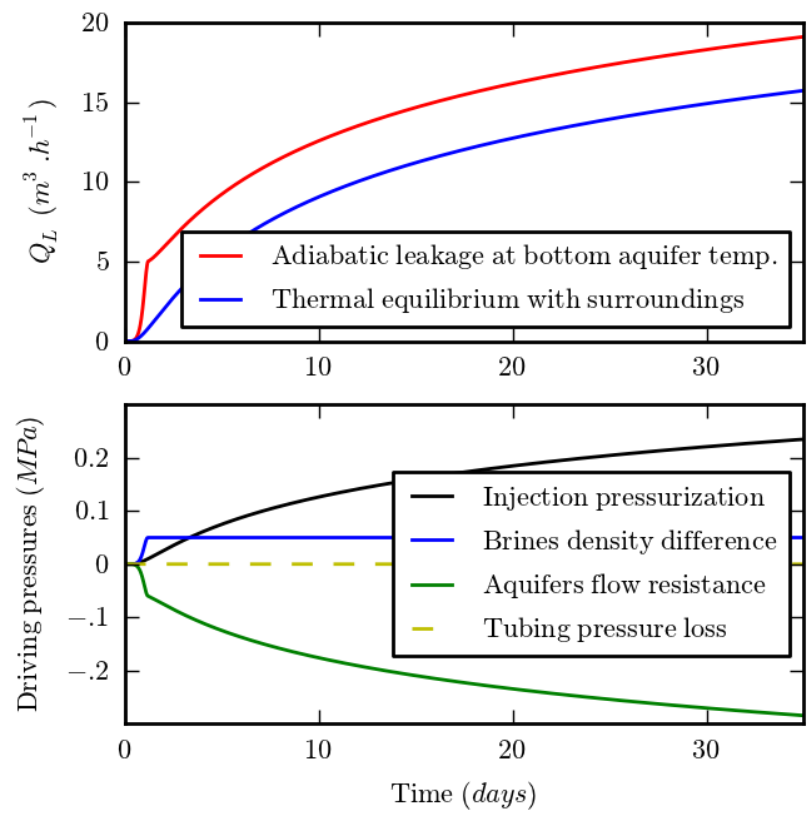

Figure 15: Example 3, case $X_{s_{-}}=0.1 \%$ (no salinity difference). Leakage rate over time (top) and pressures driving the upwards flow (bottom) for the case of adiabatic leakage. The brine density difference is created by the higher temperature of the lifting water flowing in the leak without establishing equilibrium with its surroundings (i.e., without cooling).

\section{Discussion and conclusion}

The injection of waste fluid or $\mathrm{CO}_{2}$ into deep saline aquifers will create a pressure increase that will tend to displace brine upwards if a connection (e.g., an abandoned well) exists, raising issues of possible shallow potable water pollution by saline brine intrusion. However, this upward displacement of brine is countered by progressive increase in the weight of the fluid filling the leak that occurs when the dense lifting brine from the deep saline aquifer replaces the less saline brine initially filling the leak.

This article presents a new semi-analytical solution that enables this effect to be taken into account. It is based on the linearization of brine density against depth and on the Nordbotten et al. (2004) approximate evaluation of the convolution integral, improved in two ways:

- by proposing a way to estimate the "gamma" dephasingparameter (Section 4.1); and 
- by proposing using series of monotonic functions whose sum equals the total leakage rate, to be applicable to non-monotonic or non selfsimilar leakage rates(Section 4.2).

The modelpresented uses time discretization but no spatial grid, and therefore shares advantages and drawbacks of analytical or semi-analytical models. It requires few clear parameters, and makes it possible to understand which physical mechanismsare dominant over time. It provides results in less than a minute on a standard workstation (computation time is reduced by 3 to 4 orders of magnitude compared to numerical resolution; similar gains are achieved in terms of memory use), and can therefore be used for Monte-Carlo type uncertainty analyses. It is, however, restricted by important assumptions which are difficult to overcome, such as homogeneous horizontal aquifers of constant thickness and uniform properties.

Further work could consider extending this model in several directions, such as including models of molecular diffusion and convective mixing of the lifting brine reaching the top aquifer. Similarly to models from Nordbotten et al. (2004) and Nordbotten et al. (2009), it can also be extended to multiple wells perforating multiple layers, enabling evaluation of the effects of intermediate thief zones, and be implemented as a boundary condition for representing all overlying layers in a detailed numerical model of a deep aquifer used for storage. This appears as the main option for overcoming the limited capabilities of analytical models to describe reservoirs accurately.

Finally, this model has been developed to include the effects of brine density differences due to differences in salinity and thermal conditions (adiabatic or thermal equilibrium flows). A similar approach should be possible for modeling of other problems where fluid density differences have a major influence: e.g., description of fresh cement, mud or killing fluid in a well, or the airlift effect when the intrusion of a gas (for instance $\mathrm{CO}_{2}$ ) at the bottom of an open wellbore decreases the average fluid density. 


\section{Acknowledgements}

I am gratefull to Farid Smaï, Jean-Charles Manceau and Jérémy Rohmer for sharing their knowledge. I thank Olivier Bouc and all who have supported me through this work, as well as the reviewers for their valuable comments. This work was supported by BRGM's CO2 Risks Management research project. All of the semi-analytical results were produced using the Python code SAMBA (https://github.com/arnaud-reveillere/SAMBA). 


\section{References}

Audigane, P., Chiaberge, C., Mathurin, F., Lions, J., Picot-Colbeaux, G.: A workflow for handling heterogeneous 3D models with the TOUGH2 family of codes: Applications to numerical modeling of CO2 geological storage. Computers \& Geosciences 37,610-62 (2011)

Bandilla, K.W., Kraemer, S. R., Birkholzer, J. T.: Using semi-analytic solutions to approximate the area of potential impact for carbon dioxide injection. Int. J. of Greenhouse Gas Control 8,196-204 (2012)

Battistelli, A., Calore, C., Pruess, K.: The Simulator TOUGH2/EWASG for Modeling Geothermal Reservoirs with Brines and Non-Condensible Gas, Geothermics 26 (4), 437 - 464 (1997)

Birkholzer, J.T., Nicot, J.P., Oldensburg, C.M., Zhou, Q., Kraemer, S., Bandilla, K.: Brine flow up a well caused by pressure perturbation from geologic carbon sequestration: Static and dynamic evaluations. Int. J. of Greenhouse Gas Control 5, 850-861 (2011)

Clark, J.E., Bonura, D., Van Voorhees RF: An overview of injection well history in the United States of America. Developments in Water Science 52 (2005): 3-12.

De Marsily, G.:Quantitative Hydrogeology, Academic Press, Orlando, FL (1986)

Dobossy, M.E., Celia, M.A., Nordbotten, J.M.: An efficient software framework for performing industrial risk assessment of leakage for geological storage of $\mathrm{CO}_{2}$. Energy Procedia, Volume 4, p.4207-4214 (2011)

Gasda, S.,Bachu, S., Celia M.A.: Spatial characterization of the location of potentially leaky wells penetrating a deep saline aquifer in a mature sedimentary basin, Env. Geol. 46, 707720 (2004)

Global CCS Institute (GCCSI): The Global Status of CCS: 2012,Canberra, Australia (2012)

Humez, P., Audigane, P., Lions, J., Chiaberge, C., Bellenfant, G.: Modeling of CO2 Leakage up Through an Abandoned Well from Deep Saline Aquifer to Shallow Fresh Groundwaters. Transp Porous Med 90, 153-181 (2011)

Intergovernmental Panel on Climate Change (IPCC): Special Report on Carbon Dioxide Capture and Storage. Cambridge University Press, UK (2005)

Javandel, I., Tsang, C.F., Witherspoon, P., Morganwalp, D.: Hydrologic detection of abandoned wells for hazardous waste disposal, Water Resour. Res., 24(2), 261- 270 (1988)

Mathias, S.A., Hardisty, P.E., Trudell, M.R., Zimmerman, R.W:, Approximate Solutions for Pressure Buildup During CO2 Injection in Brine Aquifers, Tran.sport in Porous Media, vol. 79, no. 2, pp. 265-284 (2009) 
Nicot J.-P., Oldenburg, C., Bryant, S., Hovorka, S.: Pressure perturbations from geologic carbon sequestration: Area-of-review boundaries and borehole leakage driving forces. Energy Procedia 1, 47-54 (2009)

Nicot, J.-P.: A survey of oil and gas wells in the Texas Gulf Coast, USA, and implications for geological sequestration of $\mathrm{CO}_{2}$. Environ Geol 57, 1625-1638 (2009)

Nordbotten, J.M., Celia, M.A. and Bachu, S.: Analytical solutions for leakage rates through abandoned wells, Water Resources Research 40, W04204 (2004)

Nordbotten, J.M., Celia, M.A. and Bachu, S., Dahle, K.:Semianalytical solution for $\mathrm{CO}_{2}$ leakage through an abandoned well, Environ. Sci. Technol. 39, 602-611 (2005)

Nordbotten, J.M., Kavetski, D., Celia, M.A.,Bachu, S.: Model for CO2 Leakage Including Multiple Geological Layers and Multiple Leaky Wells, Environmental science \& technology, vol. 43, no. 3, pp. 743-749 (2009)

Oldenburg, C., Rinaldi, A.: Buoyancy Effects on Upward Brine Displacement Caused by CO2 Injection. Transp Porous Med 87:525-540 (2011)

Phillips, S.L., Igbene, A., Fair, J.A., Ozbek, H., Tavana, M.: A Technical Databook for Geothermal Energy Utilization. Lawrence. Berkeley Laboratory Report LBL-12810, Berkeley, CA, 46 pp. (1981)

Pruess, K., Oldenburg, C.M., Moridis, G.J.: TOUGH2 User's Guide, Version 2.0.LBNL Report LBNL-43134 (1999)

Réveillère, A., Rohmer, J., Manceau, J.C.:. Hydraulic barrier design and applicability for managing the risk of $\mathrm{CO} 2$ leakage from deep saline aquifers. International Journal of Greenhouse Gas Control 9, 62-71 (2012)

Theis, C.V.: The relationship between the lowering of the piezometric surface and the rate and duration of discharge of a well using ground water storage. Trans. Amer. Geophys. Union 16, 519-524 (1935)

Tsang, C.-F., Birkholzer, J., Rutqvist, J.: A comparative review of hydrologic issues involved in geologic storage of $\mathrm{CO}_{2}$ and injection disposal of liquid waste. Environ Geol54:17231737 (2008) 